\title{
LATINO-AMERICANISMOS, CAMPOS DE PRODUÇÃO E DIFUSÃO DE CONHECIMENTO E INFORMAÇÃO SOBRE A "AMÉRICA LATINA”, E MAPEAMENTO PRELIMINAR DO CASO BRASILEIRO ${ }^{1}$
}

\author{
Flávia Lessa de Barros ${ }^{2}$ \\ Lília G. M. Tavolaro ${ }^{3}$
}

\begin{abstract}
Resumo: Partimos da discussão sobre a "América Latina" como elemento de linguagem e categoria de entendimento da realidade social sob a determinação de processos históricos e contextos geopolíticos, nos quais são conformados diferentes tipos de "latino-americanismo". Exploramos alguns aspectos relativos à institucionalização e à consolidação de iniciativas em concertação e associação no campo de produção de conhecimento e informação sobre a América Latina, com destaque da área das Ciências Sociais latino-americanas. Norteadas pela noção de "campo" bourdieusiana, apresentamos um mapeamento preliminar sobre o caso brasileiro, compreendendo um conjunto de 146 iniciativas institucionais sediadas no país e em operação, criadas nas últimas quatro décadas e meia, que têm "América Latina" como unidade de análise e foco de atuação.
\end{abstract}

Palavras-chave: América Latina. Latino-americanismo. Regionalismo e integração regional. Campos de produção e difusão de conhecimento e informação. Brasil.

\begin{abstract}
We start from the discussion about "Latin America" as an element of language and category of understanding of social reality, whose meanings are determined under specific historical processes and geopolitical contexts, in which different types of "Latin Americanisms" are formed. We explore some aspects related to the institutionalization and consolidation of initiatives in concertation and association in the field of production of knowledge and information on Latin America, with emphasis in the area of Social Sciences. Based on Bourdieu's notion of "field", we present a mapping of the institutional initiatives established in the country and in operation, created in the last forty five years, that have "Latin America" as a unit of analysis and focus of action.
\end{abstract}

Keywords: Latin America. Latin-americanism. Regionalism and regional integration. Fields of production of knowledge and information. Brazil.

\footnotetext{
${ }^{1}$ Uma primeira versão dos resultados da pesquisa que fundamenta e norteia o presente artigo, "O(s) latinoamericanismo(s) no Brasil - Mapeamento preliminar" foi divulgada na Mesa-Redonda "Campos de produção de conhecimento e informação sobre a América Latina no Brasil", no 40 Encontro Anual da ANPOCS, CaxambMG, em outubro de 2016, coordenada pelo Prof. João Feres Jr. (IESP/UERJ). Um informe com os resultados preliminares da pesquisa, intitulado "Campos de produção e difusão de conhecimento e informação sobre a "América Latina" no Brasil e dimensões sócio-político-culturais e científicas de processos de regionalização e integração regional" foi publicado no Dossiê "Las resistências", do Boletim 1/2017 do GT Integração Regional e Unidade Latino-Americana e Caribenha, do Conselho Latino-Americano de Ciências Sociais - CLACSO, em fevereiro de 2017.

${ }^{2}$ Doutorado e Pós-Doutorado em Sociologia (UnB). Professora do Departamento de Estudos Latino-Americanos (ELA) do Instituto de Ciências Humanas (ICS) - Universidade de Brasília (UnB). E-mail: flavia.barros17@gmail.com

${ }^{3}$ Doutorado em Sociologia New School for Social Research (NSSR), Estados Unidos. Professora do Departamento de Estudos Latino-Americanos (ELA) do Instituto de Ciências Humanas (ICS) - Universidade de Brasília (UnB). E-mail: liliatavolaro@ hotmail.com
} 


\section{Introdução: para mapear a produção do conhecimento e iniciativas institucionais, em busca de outras dimensões de cooperação e integração}

As comemorações do bicentenário da independência na América Latina, em parte ainda em curso ou por vir em vários países na região, como o Brasil, configuram um momento crítico ideal para o resgate e a atualização, nas Ciências Sociais e afins, das grandes temáticas do pensamento e da teoria social latino-americana e das formas relacionadas de produção e difusão de conhecimento e informação sobre a "América Latina”, na própria região e no mundo.

Sem muita visibilidade no seu conjunto para além do campo político-diplomático e das áreas da História e das Artes e em meio a controvérsias acerca do ano oficialmente definido para a contagem dos "200 anos", as agendas comemorativas do bicentenário vêm ocorrendo num cenário maior de importantes debates que transbordam a questão nacional, resgatam a relação entre nacionalismo e regionalismo desde a origem, em vários movimentos intelectuais e políticos e em sucessivos períodos no continente e são marcados por problematizações e proposições acerca do significado de América Latina e de seu "lugar" no mundo contemporâneo (Zea, 1986; Ianni, 1988; Martins, 2012; Ribeiro, 2002).

Considerando o termo "América Latina" como um elemento de linguagem e categoria de entendimento da realidade social em processos históricos e contextos geopolíticos, observamos que tais problematizações e proposições ganham em complexidade em face do que se convencionou denominar por "processos de globalização", os quais suscitam hibridismos de várias ordens e impõem revisões de algumas abordagens em voga nas Ciências Sociais e em outras áreas de conhecimento, operadoras de reducionismos sobre a "América Latina".

Ainda que, por definição, qualquer conceito implique em uma forma de reducionismo, em se tratando de conceito como o de "América Latina", que se tornou polissêmico ao longo de sua história e sob forte determinação geopolítica mundial, entre caricaturas e mistificações de cunho conservador e emancipatório, é necessário apreendermos os projetos vinculados em disputa ou com maior poder de influência, em suma, sobre os rumos das sociedades que eles encerram, bem como as metamorfoses por eles sofridas, à luz de processos mais amplos e difusos na atualidade. Na esteira dos debates em curso, não consistem em temáticas menores as ideologias e utopias constituintes ou incorporadas a tais projetos, bem como as heterotopias e distopias que vêm se manifestando em divergência ou em associação a eles, reconhecidas desde 
uma perspectiva crítica. Também atribuímos relevância à questão dos potenciais, limites e desafios dos substratos institucionais, sobretudo acadêmicos, em que ocorrem a formação das agendas e a produção e a difusão de conhecimento e informação sobre a América Latina e os países latino-americanos e caribenhos.

Ao observarmos o desenvolvimento do conhecimento produzido "sobre", "na" e "a partir da" região, identificamos como uma valorosa contribuição intelectual a sistematização de categorias, conceitos e teorias capazes de compreender e explicar as realidades da América Latina e dos países latino-americanos e caribenhos que compartilham importantes especificidades históricas e geopolíticas e, ao mesmo tempo, preservam suas particularidades. A respeito, é salutar a síntese da definição de América Latina como "una e diversa", de Geronimo de Sierra (2008), em consonância com vários autores latino-americanistas clássicos, e os desdobramentos metodológicos correspondentes, centrados na abordagem comparada.

Não obstante, para além do campo acadêmico que tradicionalmente abriga a formulação do pensamento e da teoria social latino-americana, assistimos nas últimas décadas à crescente produção e difusão do conhecimento e da informação sobre a América Latina em diversos países latino-americanos e caribenhos, envolvendo outros atores e instituições (movimentos sociais, ONGs, entidades culturais e artísticas; fundações; veículos de mídia; think tanks; órgãos governamentais, agências de cooperação e empresas privadas de vários setores), emergentes em concomitância aos processos de globalização, regionalização e integração que mobilizam os países e blocos de países na região em meio a diferentes matizes ideológicos e políticos.

No Brasil, são notáveis as iniciativas dentro e fora da academia com abordagens e perspectivas temáticas regionais latino-americanas em relação direta e indireta com tais processos. Todavia, apesar da multiplicação de debates, pesquisas e agendas para compreender e responder às diversas problemáticas implicadas por questões econômicas, políticas, sócioculturais e artísticas na região, as práticas de produção e difusão do conhecimento e informação sobre América Latina no país manifestam-se de forma fragmentada, dispersa e sem visibilidade. Em geral, são ainda pouco conhecidas e articuladas as iniciativas institucionais brasileiras existentes na atualidade, cujas abordagens e atividades têm como foco a "América Latina" e, menos ainda, "América Latina e Caribe"4.

\footnotetext{
${ }^{4}$ É sintomático, nesse sentido, que a I Reunião de Pesquisadores Latino-Americanistas e Caribeanistas tenha ocorrido apenas no $40^{\circ}$ Encontro da Associação Brasileira de Pós-Graduação em Ciências Sociais (ANPOCS), ocorrido em 2016 em Caxambu.
} 
Neste artigo, apresentamos um mapeamento preliminar do perfil de 146 "iniciativas institucionais", em operação, criadas nas últimas quatro décadas e meia no Brasil, as quais elegem centralmente a "América Latina" como unidade de análise e/ou foco de atuação e constituem o que denominamos por "campos de produção e difusão do conhecimento e informação sobre 'América Latina' no Brasil”" . Traçamos algumas características básicas desse conjunto, que nos permitem avançar na compreensão dos processos de formação, organização e funcionamento de tais campos. O objetivo é também contribuir com novos elementos para as análises sobre as possíveis dimensões sócio-político-culturais e acadêmico-científicas de processos de regionalização e integração regional na América Latina, ainda pouco conhecidas para além das convencionais dimensões políticas e econômicas.

Numa breve contextualização histórica e teórica, demarcamos inicialmente as relações entre concepções sobre a América Latina e processos históricos e geopolíticos, indicando as principais iniciativas inter-governamentais na região voltadas para a união e a integração dos países latino-americanos e caribenhos. Exploramos os desdobramentos de processos e iniciativas de integração regional que conformaram distintos "latino-americanismos", bem como alguns aspectos relativos à institucionalização e à consolidação de iniciativas em concertação no campo da produção de conhecimento sobre a América Latina, com destaque das Ciências Sociais latino-americanas, nossa área de formação e referência.

Assumindo a centralidade da noção de "campo" de Pierre Bourdieu (2004) em nosso marco teórico-metodológico inicial e amparando-nos numa perspectiva crítica do conhecimento como agente constitutivo e constituinte da realidade social e das relações de poder a ela subjacentes e como processo que não se restringe ao universo exclusivamente científico e acadêmico (Bourdieu, 2015; Berger e Luckmann, 1985; Foucault, 1978, 1980; Wallerstein et al., 1996), exploramos os critérios do mapeamento das iniciativas institucionais selecionadas, as quais transbordam expressivamente em diversas outras áreas de conhecimento e atuação. Trata-se de um primeiro grande mapa dos campos de produção e difusão de conhecimento e informação

\footnotetext{
${ }^{5} \mathrm{O}$ projeto de pesquisa que o subsidia é desenvolvido a partir do Núcleo-Rede Desenvolvimento e Democracia na América Latina - Experiências, mitos e alternativas paradigmáticas (DDAL), do PPG-ELAC/ICS da Universidade de Brasília, certificado no Diretório de Grupos de Pesquisa do CNPq. Na primeira fase (2016), contou com a colaboração da Profa. AdeliaMiglievich Ribeiro (PGCS/UFES) e com os seguintes assistentes de pesquisa: Vinícius Gürtler (Mestre em Relações Internacionais/UnB), Aryell Calmon, Emmanuel Brasil, Evelyn Silva Bernardo, Luyana Ladislau e Maria Canaan Pires Fialho (graduandos em Ciências Sociais/UnB), e Guilherme Côgo, Leonardo Muniz e Tamyres Batista (graduandos em Ciências Sociais/UFES).
} 
sobre a "América Latina" no Brasil na atualidade, delimitado segundo alguns aspectos fundamentais para os propósitos de seguimento de nossas investigações e análises.

\section{"América Latina" como elemento de linguagem e categoria de entendimento da realidade social sob a determinação de processos históricos e contextos geopolíticos}

Mesmo evocada segundo diversas perspectivas no campo semântico e do conhecimento, "América Latina" (e outros termos e expressões de larga difusão, como "latino-americano" e "latino-americanismo") é muitas vezes anunciada como um dado inquestionável da realidade e não uma categoria historicamente construída em múltiplas dimensões, política, econômica, social e cultural, e que, enquanto tal, resulta de e contribui para diferentes projetos e agendas políticas e geopolíticas que seguem em disputa em contextos específicos, ancorados por vários tipos e níveis de institucionalidade, públicos e privados. Muitos autores de referência observam que a própria origem da ideia e do nome "América Latina" é marcada por polêmicas que refletem justamente a imbricação de significados atribuídos com processos e contextos geopolíticos e as disputas neles travadas (Ardao, 1980; Bethell, 2009; Feres Jr., 2005; Phelan, 1993).

Para John Phelan (1993), a adjetivação de América Latina tem origem europeia, no âmbito das disputas imperialistas entre França e Estados Unidos, tendo sido concebida pelo conselheiro de Napoleão III, Michel de Chevalier, em 1836, e desdobrada num outro novo termo, "panlatinismo", que expressava o projeto de dominação francesa nas Américas. Na mesma direção, Arturo Ardao (1986) reconhece a origem panlatinista do termo "América Latina" (e suas variantes gramaticais como o "latino-americanismo") no contexto dos "panismos" no século XIX na Europa, movimentos internacionais pela reunião, em torno a um centro dominante, de países e povos que apresentavam vínculos étnicos, linguísticos e culturais. Segundo o autor, sob a mesma influência foi idealizado o "pan-americanismo", desde os Estados Unidos, por James Blaine, o primeiro panismo de caráter geográfico e continental, que preservava interesses políticos sem recorrer a referências étnicas e culturais comuns outrora essenciais.

Ardao (1986) também atribui a designação "América Latina" (ou "Latinoamérica”) de uma nova região no mundo com identidade própria à obra de intelectuais hispano-americanos, 
fixados em Paris e na região, em resistência aos avanços imperialistas do "Norte" sob a égide da Doutrina Monroe (1823), reinterpretada pela doutrina do "Destino Manifesto" (1845). Tratava-se de um novo conceito histórico que compreendia a revisão das relações da região com a Europa e os Estados Unidos. O autor se refere a uma "confrontação dialética" e a uma "transmutação dialética" ao analisar o processo de apropriação e reinvenção do latinoamericanismo de inspiração pan-latinista pelo hispano-americanismo, segundo outros projetos políticos construídos desde a própria região. No entanto, o pan-americanismo latino-americano teria sido sujeito a ambiguidades e conflitos desde sua origem, sobretudo pela presença dos Estados Unidos e sua agenda expansionista e imperialista, mas também pela adoção de “América" e "americanista" como referências mais gerais em oposição à "Europa".

Outros diversos autores, principalmente historiadores, filósofos e cientistas sociais, também discorrem a respeito de como, desde os primórdios das lutas de independência, no início do século XIX, a ordenação sócio-político-econômico-cultural dos países latinoamericanos e caribenhos, em alguma medida, segundo cada país, era idealizada em escala regional, envolvendo a união dos povos americanos. Para Leslie Bethell (2009: 292), por exemplo, apesar da fragmentação da América espanhola a partir dos processos de independência, políticos e intelectuais hispano-americanos em meados do século XIX enalteciam a necessidade de uma consciência e uma identidade latino-americanas comuns, para a superação dos nacionalismos locais e o enfrentamento dos projetos imperialistas dos países do Norte na região. Bethell relembra que, desde então, em grande medida, a política externa brasileira se manteve alheia a esse projeto, tendo privilegiado o estreitamento das relações políticas e comerciais com os Estados Unidos e a Europa, numa clara resistência à identificação com a América Latina (Bethell, 2009:295-296). Algo, aliás, que encontrava reciprocidade de ideólogos latino-americanistas que viam o escravismo e o regime imperial brasileiros como avessos aos princípios republicanos vigentes na maior parte das nações recém independentes da América espanhola.

Segundo Ardao (1986) desde o final do século XIX, o americanismo hispano-americano evoluiu entre dois movimentos, o pan-americanismo e o latino-americanismo, que teriam apresentado um importante nexo histórico, como "conceitos confrontados" e por "momentos enfrentados" no decorrer de longas disputas nas arenas inter-governamentais que se procurava estabelecer. Em termos político-institucionais, a União Latino-americana concebida por José Maria Torres Caicedo foi vencida frente à União Americana e à União Pan-americana e, por 
sua vez, o americanismo ou o pan-americanismo estadunidense foi convertido no interamericanismo, com a substituição da União Pan-americana pela Organização dos Estados Americanos (OEA), em 1948, mesmo ano da criação da Comissão Econômica para a América Latina e o Caribe (CEPAL), no âmbito das Nações Unidas. Munida por um aparato jurídico mais complexo, a OEA representava a "revisão orgânica" do pan-americanismo no marco regional, enquanto a CEPAL significava o reconhecimento do latino-americanismo no marco internacional, contribuindo para que este deixasse de ser um "conceito submerso" e alçasse a institucionalização internacional nas arenas de governança global ${ }^{6}$.

Em suma, são a princípio distintas duas grandes perspectivas integracionistas para a região, as quais participaram diversamente na conceituação “América Latina”. Por um lado, a latino-americana, em prol da auto-determinação dos povos e da maior autonomia do desenvolvimento dos países latino-americanos e caribenhos, combinando crescimento econômico, bem-estar social e preservação da identidade cultural. Estes ideais implicavam em esforços dos países latino-americanos e caribenhos por melhores posições na hierarquia compreendida pela divisão internacional do trabalho desde o período colonial - atualizada sob os imperialismos - e, por conseguinte, de condições mais favoráveis no sistema mundial.

A perspectiva latino-americana norteou movimentos insurgentes e revolucionários em vários países na América Latina e no Caribe, que atravessaram o século XX e adentraram o século XXI. Persistentes através de gerações de intelectuais e políticos latino-americanos ${ }^{7}$, os projetos subjacentes inspiraram importantes vertentes nas Ciências Sociais e áreas afins no século XX. Também imbuíram iniciativas inter-estatais de integração mais recentes, sobretudo no início do século XXI, com a ascensão dos governos mais "progressistas" e de esquerda em vários países na região, os quais vieram a propugnar novos modelos alternativos de união e integração regional, em contraposição aos estabelecidos desde o Pós II Guerra Mundial, com a participação e a influência direta e indireta dos EUA.

\footnotetext{
${ }^{6}$ Ainda segundo Ardao (1986), a despeito de divergências doutrinárias e diplomáticas, iniciativas institucionais emergentes de tal cenário, como a União das Universidades Latino-Americanas e Caribenhas (UDUAL), em 1949, com o apoio da OEA e da Organização das Nações Unidas para a Educação Ciência e Cultura (UNESCO), o Parlamento Latino-Americano (PALA), em 1969, e o Sistema Econômico Latino-Americano (SELA) em 1975, entre outras, tiveram o mérito de contribuir para a visibilidade do latino-americanismo no mundo.

${ }^{7}$ É mister resgatar a avaliação de Ardao (1996), coadunada com as visões de José Martí ("Nuestra América") e Ariel de Rodó ("Pátria Grande") de que, para além de uma mera estratégia regionalista, diferentemente da trajetória do pan-americanismo e do inter-americanismo estadunidenses, o desenvolvimento do latino-americanismo teria representado a promoção de uma nacionalidade em escala continental e em oposição à América anglo-saxã.
} 
Por outro lado, tem-se a perspectiva integracionista dos EUA, no mesmo período da emergência do pan-americanismo latino-americano, em prol da continuidade da subordinação dos países latino-americanos e caribenhos após a independência, como provedores de matériasprimas e consumidores de produtos industrializados, com vistas ao fortalecimento do capitalismo industrial naquele país. Desde então, é identificada a gênese de matrizes discursivas que valeram para a naturalização do imperialismo estadunidense no imaginário social, no continente americano e, a partir deste, noutras partes do mundo. Já em seus primórdios, o panamericanismo subjacente ao monroísmo alavancavam os interesses imperialistas de expansão territorial e comercial dos EUA, sendo a pretendida "integração" deste país com os países latino-americanos e caribenhos terminantemente determinada pelo livre-comércio.

As tendências do século XIX foram acentuadas ao longo do século XX, de modo que a política externa estadunidense, de forte intervencionismo militar na América Latina, tornou-se ainda mais crucial para a hegemonia econômica e política dos EUA no sistema mundial, em face da rivalidade com a União Soviética e sob o modelo geopolítico bipolar no Pós II Guerra, de acordo com a formulação de Immanuel Wallerstein $(2004,1984)$. De forma mais difusa, nos planos social, cultural e científico, foram eficazes as investidas ideológicas dos EUA na região, em meio à Guerra Fria, através de programas de filantropia e cooperação técnica (operados por grandes agências e fundações junto a governos e setores das sociedades civis, envolvendo agendas de universidades e mobilizando intelectuais, não menos na área de Ciências Sociais) e de indústrias culturais e de comunicação de massas, disseminadoras de valores estadunidenses - "americanos" - e do american way of life.

Conforme os poderes determinantes, as ideias e estratégias de integração na região latino-americana podem compreender a perpetuação ou a tentativa de mudança, em múltiplas dimensões (não apenas política, econômica e militar, mas também tecnológica, científica e epistemológica), das relações de dominação subjacentes ao modelo de interdependência "centro-periferia". Estas relações foram reproduzidas desde a colonização e sob diferentes ciclos econômicos, configurações políticas e tendências filosóficas, com traços comuns fundamentais, mas também particularidades relevantes entre os países na região, o que também contribui para ambiguidades e contradições nos desdobramentos e concorrências entre as principais tendências e estratégias. 


\section{"Estudos de área" e contrapontos teóricos e epistemológicos desde a América Latina em face dos projetos de desenvolvimento, regionalização e integração}

Um importante resultado dos processos de reestruturação do capitalismo e das agendas da cooperação internacional Norte-Sul, a partir de meados do século XX, que não se apresenta com o mesmo grau de evidência de outros impactos decorrentes de tais processos, foi a organização e a reorganização de campos de produção e difusão de conhecimento e informação em prol da "modernização" e do "desenvolvimento econômico e social” em âmbito mundial.

Não apenas foram sujeitos a enquadramentos e condicionantes os fluxos de modelos de ciência e tecnologia e educação nas relações entre "países desenvolvidos" e "países em desenvolvimento" (ou "Norte-Sul"), como também o conhecimento e a informação sobre os diversos países do mundo e suas respectivas regiões e sub-regiões tornaram-se vantajosos instrumentais para a eficácia de interesses nacionais e posições de poder de determinados países no sistema mundial (Wallerstein et al., 1996; Hettne, 1990). Assim, foram renovadas ao longo do século XX tendências observadas desde o colonialismo, quando mesmo cientistas sociais, em algumas vertentes referidas como clássicas, serviam aos interesses de grandes empreendimentos mercantilistas usurpadores e escravagistas no além-mar.

Como observa Walter Mignolo (2005), assiste-se a um salto na produção do conhecimento sobre as regiões mundiais nesse período. Com efeito, até então, a produção do conhecimento e a formação do "pensamento social" nas metrópoles e ex-colônias são majoritariamente atribuídas a elites de intelectuais, lideranças políticas, religiosos, jornalistas, artistas, diplomatas aristocráticos e estrategistas militares e comerciais. Não obstante, a importância atribuída ao "saber especializado", materializada pela geração e difusão de conhecimento e informação em maior escala, resultou na ampliação de instituições e atores envolvidos na consolidação dos estudos regionais ou "estudos de área" na Europa. São tomadas como objeto as demais regiões do mundo, especialmente "América Latina”, “Ásia” e "África”, construindo-se poderosas metanarrativas dinamizadoras de disputas

\footnotetext{
${ }^{8}$ Tal fato é observado especialmente através da expansão do ensino superior de cunho universitário, mas também da emergência de diversos tipos de centros, institutos e agências de pesquisa, consultoria e assessoria, bem como de setores técnicos e de inteligência, governamentais e de organismos internacionais, além de empresariais, vinculados a grandes corporações.
} 
na constituição de superestruturas globais de governança, com impactos locais e nacionais imensuráveis 9 .

No que tange à abordagem dos estudos de área sobre a "América Latina”, João Feres Jr. (2005:88) registra o surgimento dos Latin American Studies (LAS) nesse mesmo período nos EUA, em especial a partir da Revolução Cubana, então vista como grande ameaça ao seu poderio na região. Segundo Feres Jr., os LAS promoveram uma conceituação científica de Latin America que apresenta notáveis continuidades com o senso comum e o discurso político etnocêntrico predominante nos EUA desde o século anterior, sobre a "América Hispânica", corroborando para a vulgarização de uma concepção reificadora e estigmatizante da região e de seus povos originários ${ }^{10}$. Ruy Mauro Marini (1993) nota que visão semelhante havia sido replicada, de meados do século XIX a meados do século XX, por destacados intelectuais latinoamericanos de diferentes correntes políticas, filosóficas e teóricas que, ao buscarem promover reflexões sobre a própria natureza, combinaram o enfoque racista com a doutrina do liberalismo assimilada nos processos de independência e de fundação dos Estados na região ${ }^{11}$.

$\mathrm{Na}$ perspectiva da institucionalização, diferentemente do acontecido nos EUA, o empreendimento intelectual na América Latina no período não se traduziu, contudo, em um número significante de centros de estudos de área ou núcleos de pesquisa e informação especificamente voltados para a região. Segundo Pablo Gentili e Fernanda Saforcada (2010:7), os projetos acadêmicos e políticos de alcance regional em prol do fortalecimento de uma agenda latino-americanista comum no campo do conhecimento, anti-imperialista e anti-colonialista, foram ferrenhamente prejudicados pelas ditaduras que se sucederam na região entre as décadas de 1960 e 1980, o que concorreu, entre outros fatores, para o desenvolvimento desigual e assincrônico dos cursos de pós-graduação, cuja dinâmica de crescimento caracterizou-se

\footnotetext{
${ }^{9}$ Conforme descreve Vicente Rafael (1994:93), o livro de Robert Hall - então membro do Social Science Research Commitee - publicado originalmente em 1947 e intitulado Area Studies: With Special Reference to Their Implications for Research in the Social Sciences reivindica a imediata institucionalização dos estudos de área com base em três justificativas principais: 1) a continuidade com os campos tradicionais das humanidades; 2) a promessa de promover consensos interdisciplinares entre as humanidades e as ciências sociais e, por fim 3) a utilidade para o treinamento de bons cidadãos capazes de salvaguardar os interesses nacionais americanos, após a II Guerra Mundial e face a perspectivas de outras guerras futuras.

${ }^{10}$ Feres Jr.(2005) demonstra que tal abordagem definia a América Latina como região composta por sociedades tradicionais e atrasadas, pautadas amplamente em crenças pré-científicas e em laços primordiais de família, no particularismo e na difusão do elitismo e em organizações políticas amparadas na hierarquia, na hereditariedade e nos costumes, em contraposição à moderna sociedade estadunidense, onde imperariam, ao contrário, valores democráticos e conhecimento científico, o universalismo, o individualismo e o igualitarismo.

${ }^{11}$ Para Marini (1993), foram poucos os pensadores que já no começo do século XX enfrentavam o enfoque racista na região, como Alberto Torres e José Martí.
} 
basicamente pela "heterogeneidade da oferta, sua segmentação e diferenciação". Em geral, o pensamento latino-americano foi invisibilizado e fragmentado em disciplinas temáticas que tratavam de assuntos relacionados à região ${ }^{12}$.

Por outro lado, conforme lembra Bethell (2009), foi precisamente no contexto da Guerra Fria e da constituição do "Terceiro Mundo", que a identidade latino-americana tornou-se mais expressiva no Brasil, tendo sido a ressignificação da América Latina no país resultado de movimentos de intelectuais, muitos desde o exílio, contrários e em resistência ao regime militar apoiado pela política externa estadunidense. De fato, no cenário reconfigurado do Pós II Guerra Mundial, prestigiados intelectuais latino-americanos - dentre eles brasileiros - críticos às teorias da modernização e do desenvolvimento então dominantes, dedicaram-se à formulação de alternativas para os dilemas do capitalismo dependente na América Latina, contribuindo para um latino-americanismo a partir da região que resgatava ideais integracionistas gestados no decorrer do século XIX e na virada do século XX.

Destacaram-se inicialmente as abordagens do estruturalismo latino-americano da CEPAL. Em concordância com inúmeros autores, Ricardo Bielschowsky (2010:11) rememora os textos inaugurais do economista Raúl Prebisch, que continham os elementos centrais da teoria estruturalista cepalina, a qual explicava as limitações e obstáculos do desenvolvimento na América Latina pelas condições estruturais específicas da região enquanto periferia do capitalismo. Com grande repercussão entre os chamados “países do Terceiro Mundo”, Prebisch (seguido pelo brasileiro Celso Furtado, com uma perspectiva histórica de mais longo prazo) criticava a teoria econômica geral por seu "falso princípio de universalidade" e denunciava a divisão internacional do trabalho prevalecente, geradora de concentração de riquezas nos países exportadores de manufaturados, em detrimento dos países exportadores de produtos primários - o que veio a ser duramente acirrado com o "neo-extrativismo" sob o neoliberalismo.

Face aos debates desencadeados pela CEPAL emergiu a teoria da dependência, efervescente nas décadas de 1960 e 1970, formulada por intelectuais latino-americanos (e, em especial, brasileiros) que traziam novas alternativas para se pensar a "América Latina”. Como enfatiza Carlos Eduardo Martins (2004), os teóricos da dependência, em suas diferentes

\footnotetext{
${ }^{12}$ Gentili e Saforcada (2010:11) reiteram a preocupação que atravessava os estudos promovidos pelo CLACSO, no final da década de 60, sobre o colonialismo cultural e acadêmico na área de Ciências Sociais e destacam a necessidade de consolidação de uma agenda própria da região para a região, gravemente ameaçada pela fuga de cérebros causada pelas ditaduras militares e as políticas de cunho neoliberal que resultaram no encolhimento de investimentos públicos em educação.
} 
vertentes, de influência marxista e de cunho weberiano, romperam com o nacionalismo metodológico imperante nas teorias da modernização e nas teorias desenvolvimentistas da $\mathrm{CEPAL}^{13}$. Ao invés da análise linear e etapista do subdesenvolvimento como processo única e exclusivamente resultante de experiências nacionais de colonização e de decisões equivocadas de elites locais, as teorias da dependência o concebiam como fenômeno próprio da hierarquização e da marginalização impostas pela divisão internacional do trabalho. Sob este prisma, o subdesenvolvimento latino-americano revelava-se como parte constitutiva e necessária ao desenvolvimento das economias capitalistas centrais e não necessariamente como um antagonismo (Martins, 2004: 17-18).

Para estruturalistas cepalinos e teóricos dependentistas, a crise do capitalismo internacional, do final da década de 1960 e começo da década de 1970, era uma oportunidade de retomada da agenda desenvolvimentista, viabilizada desde fins da década de 1940, e de planos de integração de caráter mais autônomo para os países da região. O período de grande formulação teórica da dependência correspondeu à primeira fase de iniciativas de integração na América Latina e Caribe no Pós II Guerra, da década de 1960 até a década de 1980, caracterizada justamente pelo objetivo de fortalecimento e inserção das economias nacionais no mercado internacional, com forte protagonismo de estratégias estatais ${ }^{14}$.

Na busca de um equilíbrio macro-econômico internacional para aplacar a crise da dívida externa dos países periféricos na década de 1970, a solução ditada das arenas de governança global com ascendência sobre os processos de regionalização, em contraposição às demandas da New International Economic Order (NIEO), sob a liderança de Prebish (primeiro secretáriogeral da United Nations Comission on Trade and Development (UNCTAD), foi a maior sistematização dos preceitos neoliberais utilitaristas da Escola de Chicago, adotados na

\footnotetext{
${ }^{13}$ As principais referências da corrente de influência marxista seriam Theotonio dos Santos, Ruy Mauro Marini, Vânia Bambirra e Orlando Caputo, e as da corrente de cunho weberiano, Fernando Henrique Cardoso e Enzo Faletto.

${ }^{14} \mathrm{Em}$ tal direção, algumas das iniciativas de integração econômica regional predominantes na América Latina e no Caribe no período foram a Associação Latino-Americana de Livre Comércio (ALALC), criada em 1960, o Mercado Comum Centro Americano (MCCA), também criada em 1960; a Associação de Livre Comércio do Caribe (CARIFTA), criada em 1968; a Comunidade Andina (CAN), em 1960, a Comunidade do Caribe, em 1973 e a Associação Latino-Americana de Integração (ALADI), em 1980, mais tarde substituída pela Área de Livre Comercio das Américas (ALCA), em 1994. O Sistema Econômico Latino-Americano e do Caribe (SELA), criado em 1975, que resgatava alguns dos princípios de concertação política inter-governamental entre os países na região com maior independência dos EUA, compreendidos na proposição da União Sul-Americana, em 1953, apenas alcançaria alguma maior perspectiva de viabilidade em 2005, mediante a sua refundação, com a SELAC.
} 
América Latina desde o Governo Pinochet, no Chile (1970), o que terminou resultando no Consenso de Washington (1989). Como também vastamente discutido na literatura temática, a América Latina foi tomada como um grande laboratório de reformas neoliberais. Os "ajustes" às necessidades do capitalismo globalizado, caracterizados pela austeridade financeira, privatizações e redução do papel de regulação do Estado, provocaram desajustes e crises que impossibilitaram o desenvolvimento equilibrado nos países latino-americanos e caribenhos e noutras regiões (Borón, 2002, 2003; Cruz, 2007; Martins, 2011; Wallerstein, 1995; Zurbriggen, 2007).

A despeito de valiosas contribuições críticas desde o estruturalismo cepalino na sua primeira fase e das correntes teóricas da dependência para o pensamento e a teoria social na região e para alternativas de cunho mais global perante o sistema internacional capitalista, os princípios e as perspectivas integracionistas latino-americanas e caribenhas alternativas e emancipatórias, gestados no século XIX e começo do século XX para o desenvolvimento das economias nacionais, não alcançaram ambiente efetivamente favorável diante do avanço do imperialismo estadunidense no contexto de regimes autoritários e ditatoriais nas décadas de 1960, 1970 e 1980. Tais perspectivas tampouco foram favorecidas no período posterior, a partir do final da década de 1980 e início da década de 1990, em que se assistiu a movimentos de redemocratização combinados com a emergência do neoliberalismo na região, fenômeno que, como observa Edgardo Lander (2006) reabilitou as chamadas "democracias de mercado" nos países latino-americanos ${ }^{15}$.

A partir da década de 1990, no contexto do esvanecimento da Guerra Fria e de reordenações no sistema internacional influenciadas pelo Consenso de Washington, observamos uma nova fase de iniciativas de integração política e econômica regional na América Latina. Essas iniciativas são impulsionadas por mecanismos de políticas e instituições supranacionais predominantemente orientados pelo modelo do "regionalismo aberto", formulado pela CEPAL segundo a abordagem do "neo-estruturalismo" (Rodriguez, 2009), o qual, segundo alguns críticos, enveredou em um franco retrocesso em relação às abordagens cepalinas anteriores.

\footnotetext{
${ }^{15}$ Por exemplo, Marini é reconhecido por conceber uma integração alternativa, em prol de um espaço econômico na região mais amplo e inclusivo, com o desenvolvimento de novas superestruturas políticas e jurídicas para além de meras estratégias comerciais, de modo a também compreender um grande projeto político e cultural que resgatasse a tradição da esquerda latino-americana e fizesse frente aos projetos de integração em formação no Norte, com destaque da União Européia - cenário no qual, a princípio, o MERCOSUL seria uma grande aposta.
} 
Sob o avanço da globalização do capitalismo, as iniciativas de integração da América Latina resultaram na formação de novos blocos de países, na criação de novas instituições e na reestruturação de instituições pré-existentes, para viabilizar o acesso das economias nacionais aos mercados globais, norteadas pelo princípio do livre-mercado. No período, a noção de "integração regional hegemônica" na América Latina era bastante restrita, voltada para processos econômicos e comerciais. Havia pouca ênfase nas dimensões político-institucional, sócio-cultural-científica e ambiental e, muito menos, numa identidade transnacional continental, segundo os termos então definidos pela União Europeia ou como propugnado por vertentes latino-americanistas alternativas até então (Saludjian, 2004) ${ }^{16}$. Borón (2006) destaca a prevalência do neoliberalismo na América Latina desde então, não apenas como política econômica, mas como "modelo normativo de organização social e filosofia integral”, com forte impacto sobre as instituições de produção de conhecimento e pesquisa e efeitos deletérios sobre a possibilidade da continuidade e renovação de um pensamento crítico na região.

Todavia, tal situação não impediu novas abordagens no campo da chamada teoria crítica latino-americana nas últimas décadas, no seu conjunto consideradas constituintes de uma terceira grande corrente teórica do pensamento e da teoria social e política do pensamento latino-americano. Essa corrente, mais multifacetada que as da CEPAL e da teoria da dependência, implicaria em novas formas de representação sobre a "América Latina”, segundo seus proponentes, as quais também constituíram arenas de debates e oposição às iniciativas mais atreladas ao modelo estadunidense e tornaram-se fonte de inspiração para iniciativas de integração "pós-neoliberal" na última década, em suas pretendidas tendências contrahegemônicas e anti-sistêmicas.

A ascensão de governos progressistas e de esquerda em países latino-americanos na década de 2000 representou a abertura de uma nova fase nos processos de integração na região, que poderia finalmente resultar em oportunidades para mudanças nas condições de inserção da região no sistema capitalista mundial. Nos planos nacional e internacional, não sem significativas contradições, tais governos teriam procurado atuar em prol do resgate da dimensão política, do Estado, do próprio sentido de desenvolvimento e de um novo projeto para a América Latina (Carcanholo e Saludjian, 2013).

\footnotetext{
${ }^{16}$ Pautados a princípio por este modelo, foram criados o Mercado Comum do Sul (MERCOSUL), em 1991, o Tratado de Livre Comércio da América do Norte (NAFTA), em 1992; o Grupo dos Três, em 1994; a Associação de Estados do Caribe, em 1994; a Área de Livre Comércio Sul-Americana (ALCSA), em 1993, e a Área de Livre Comércio das Américas (ALCA), em 1994.
} 
Concomitante a esse processo, observa-se a ascensão de abordagens no marco da teoria crítica latino-americana com fortes referenciais geopolíticos, de cunho comunitarista e proposições de radicalização da democracia, as quais visam a uma "virada epistemológica", de modo a compreender "saberes" de sujeitos sociais até então desconsiderados nos campos do conhecimento, como os movimentos indígenas, de mulheres, camponeses e afro-descendentes. Este seria, por exemplo, o eixo condutor da chamada perspectiva da "decolonialidade" (do poder e do saber) que, ao criticar interpretações eurocêntricas acerca da modernidade e seus desdobramentos para a compreensão dos processos políticos, sócio-culturais e econômicos na América Latina, clama por um exercício de "desprendimento e abertura" para dar voz às perspectivas dos povos colonizados como condição primeira de superação da colonização epistêmica (Mignolo, 2007).

Foram três as principais iniciativas inter-estatais de integração regional alternativas na América Latina e Caribe permeáveis às orientações pós-neoliberais, contra-hegemônicas e antisistêmicas, com vistas à superação do neoliberalismo, compreendidas numa terceira fase de iniciativas de integração regional, em contraposição a estratégias de iniciativas pré-existentes ${ }^{17}$. A despeito de algumas diferenças relevantes entre estas, mais importante é observar, a princípio, para o propósito do presente artigo, que ALBA-TCP, UNASUR e CELAC têm em comum, oficialmente, a missão de promover o desenvolvimento soberano, justo e solidário na América Latina e Caribe, com base na formação de uma identidade política regional compartilhada e no estabelecimento de articulações e de cooperação Sul-Sul no continente ${ }^{18}$.

Como tem sido avaliado, a crise de grande parte dos governos progressistas e de esquerda, e o avanço de forças conservadoras e neoliberais, na região e entre os países centrais no sistema mundial, vêm conformando limites aos impulsos pós-neoliberais contrahegemônicos que marcaram a constituição de projetos de cooperação e integração regional na década de 2000, e, principalmente, inviabilizando seus vetores de caráter anti-sistêmico.

\footnotetext{
${ }^{17}$ A primeira foi a Aliança Bolivariana para os Povos de nossa América (ALBA), criada em 2004, a segunda, a União das Nações Sul-Americanas (UNASUR), criada em 2008 e, a terceira, a Comunidade de Estados LatinoAmericanos e caribenhos (CELAC), criada em fevereiro de 2010.

${ }^{18}$ As abordagens multidimensionais nas propostas alternativas de integração destas três instituições também compreendem a ênfase nas dimensões sócio-cultural e ambiental e aspiram a maiores possibilidades de interrelação destas duas dimensões com a econômica e comercial, tradicionalmente priorizada por outras iniciativas de integração anteriores desde o Pós II Guerra Mundial, com vistas à ampliação dos direitos nas arenas políticas em escalas internacionais-regionais na América Latina.
} 
Desde as últimas décadas, são computados os efeitos nefastos das políticas neoliberais sobre as instituições públicas de ensino e pesquisa na América Latina, as quais haviam abrigado e gestado boa parte do pensamento crítico latino-americano, com impactos sobre suas estruturas, dinâmicas institucionais e gestão de recursos, também envolvendo restrições dos fundos da cooperação internacional, Norte-Sul e Sul-Sul. Tais tendências despontam, portanto, como grave ameaça aos processos de integração no plano político e cultural, sobretudo se considerarmos, como Borón (2006: 5), no que tange à produção do conhecimento, que a aplicação da agenda neoliberal na região implica na prevalência do "modelo de consultoria", financiado por agências privadas, no interior da própria universidade pública, o qual impacta negativamente sobre as reais possibilidades de consolidação e poder de influência de um pensamento crítico, pautado pela formação de intelectuais orgânicos, partícipes ativos da vida pública e não exclusivamente entocados em uma "vida acadêmica".

\section{Institucionalização de articulações e associações latino-americanistas. Alguns potenciais, limites e desafios}

Em meio às grandes adversidades políticas e econômicas na região, todavia, observa-se a continuidade de importantes iniciativas de articulação em defesa de agendas latinoamericanistas, com reflexões em torno das características, possibilidades, ou obstáculos ao desenvolvimento e à democracia, envolvendo pesquisadores e intelectuais latino-americanos de diferentes matrizes teóricas, metodológicas e disciplinares, em especial na área das Ciências Sociais, em prol da formação de um pensamento voltado para os problemas específicos da região. Os esforços empreendidos no âmbito acadêmico e especializado para consolidar institucionalmente a produção do conhecimento na área das Ciências Sociais na América Latina materializaram-se em associações científicas e acadêmicas regionais, tais como a Associação Latino-Americana de Sociologia (ALAS), fundada em 1950; a Faculdade Latino-Americana de Ciências Sociais (FLACSO), em 1957, e o Conselho Latino-Americano de Ciências Sociais, em 1967.

Pioneira (primeira associação de caráter regional da disciplina em nível global, fundada durante o I Congresso Internacional da Associação Internacional de Sociologia [ISA], em Zurich), a ALAS propunha contribuir para o desenvolvimento das Ciências Sociais na América 
Latina e promover uma plataforma de pensamento sobre a região e suas particularidades à luz do pensamento sociológico, com abertura para outras áreas de formação disciplinar, e com ênfase no ensino e na profissionalização. Contudo, um dos principais obstáculos ainda identificados desde a ALAS na construção de um pensamento social crítico e autônomo a partir da América Latina é a falta de integração acadêmico-científica entre intelectuais e cientistas sociais latino-americanos em torno de problemas comuns que afetam a região, tomando-se como referência pesquisas e perspectivas elaboradas face a problemáticas impostas pela região ao pensamento social (Barros, 2011). A despeito do significativo crescimento da participação nas agendas promovidas pela ALAS, numa ampla diversidade de temáticas, considera-se que a produção sociológica latino-americana ainda se caracteriza pela predominância de referências teóricas gestadas desde a Europa e dos Estados Unidos.

Como destacam Gentili e Saforcada (2010: 9), o CLACSO e a FLACSO também foram criados a partir do reconhecimento de alguns expoentes intelectuais latino-americanos acerca da necessidade de propostas inovadoras com maior poder de influência sobre a formação superior dos pesquisadores sociais, por meio de um sistema de pós-graduações em concertação regional, que pudesse embasar uma nova geração de pesquisadores sociais latino-americanos e caribenhos, capazes de conceber um pensamento autônomo, para e a partir da região. Com efeito, a FLACSO consolidou sua rede de programas em parceria em vários países, atraindo outros, e o CLACSO vem apresentando um transbordamento das alianças e filiações, para além das associações latino-americanas, com o envolvimento de entidades de outras regiões, conforme registrado em sua assembleia de 2015.

No entanto, Gentili e Saforcada (2010) verificam que a compensação do déficit de ofertas institucionais nas Ciências Sociais por opções fora da região prejudica, mais do que ajuda, o desenvolvimento acadêmico nos países latino-americanos, resultando na formação de pesquisadores com pouco conhecimento e efetivo interesse acerca das problemáticas regionais, além de mais suscetíveis à visão colonial predominante na formação norte-americana e europeia. Outro problema crucial, relacionado a esse, refere-se à imposição do inglês como "língua universal" nas principais arenas acadêmico-científicas internacionais das Ciências Sociais, como, por exemplo, na ISA, a exemplo de outras áreas do conhecimento, o que tende a gerar marginalizações nos campos e nas redes promovidas por tais arenas, bem como no sistema internacional de referência de avaliação de produção acadêmica, dificultando a 
desprovincianização dessa área de conhecimento na região, conforme ressaltado já há vinte anos por Wallerstein (1996), no relatório da Comissão Gulbenkian.

Em seus desenvolvimentos, articulações como ALAS, CLACSO e FLACSO, somaramse a movimentos internacionais mais amplos, voltados para uma agenda "Sul-Global", fomentando perspectivas alternativas de formulação teórica nas Ciências Sociais a partir de processos, trajetórias regionais e nacionais, em diferenciação a visões hegemônicas ditadas pelo eixo europeu e anglo-saxão. Ao mesmo tempo, as redes estabelecidas por essas associações e suas vertentes temáticas vêm viabilizando fluxos de intercâmbios transnacionais relevantes para possíveis sínteses teóricas que engendrem novos paradigmas, com maior poder de universalidade e contraposição às concepções estreitas e enviesadas dos paradigmas hegemônicos.

Nesse sentido, a vocação interdisciplinar seria um potencial meritório entre iniciativas de articulação latino-americanistas como ALAS, CLACSO e FLACSO. Wallerstein (1996), por exemplo, ao se referir sobre os dilemas e os potenciais da interdisciplinaridade nas Ciências Sociais na contemporaneidade (à luz do histórico de experimentação estrutural no sistema universitário nos EUA, mais destacado, mas também em outras regiões), reconhece o êxito da FLACSO no incremento de alternativas de formação e investigação para além das fronteiras disciplinares e reforça a pertinência de tal enfoque para a construção de uma ciência social não eurocêntrica na América Latina. Em diálogo com Wallerstein, Francisco Lopez-Segrera (2005) reforça tal visão, julgando serem imprescindíveis os esforços no sentido de consolidar pesquisas e abordagens interdisciplinares na região. Para o autor, a interdisciplinaridade propicia perspectivas ideográficas e nomotéticas, características do legado do pensamento humanístico e crítico latino-americano, comprometido pela falta de uma política de investimento em ciência e pesquisa continuada na região.

É indispensável a menção à LASA (Latin American Studies Association) na história das articulações e associações acadêmicas com foco na América Latina, também dedicada a debates, pesquisa e ensino sobre a região, de cunho multi e interdisciplinar. A LASA é apresentada como a maior associação de estudos latino-americanos do mundo, envolvendo as mais diversas áreas de conhecimento nas humanidades, sendo diferenciada das anteriores, genuinamente latino-americanas, por sua origem e estrutura. Criada em 1966 nos EUA, a LASA 
foi marcada pela grande predominância de acadêmicos deste país ${ }^{19}$. No início da década de 1970, a LASA já era palco de acalorados debates entre intelectuais e pesquisadores estadunidenses e latino-americanos, sendo estes últimos, mobilizados pela teoria da dependência, acusados de "politização" daquela arena acadêmico-científica. Como relata Packenham (1992), para além das abordagens teóricas, as divergências desafiavam as normas e práticas acadêmicas convencionais, que primavam pela separação entre ciência e política.

Críticas e demandas por novas formas de organização do trabalho, com ligação mais direta com a ação social, e em prol de uma ciência social anti-status quo, passaram a também incluir acadêmicos latino-americanos nos EUA na defesa de outras perspectivas, como, por exemplo, dos Latino Studies, em oposição aos Latin American Studies ${ }^{20}$. O caso da LASA demonstra com maior evidência como arenas acadêmicas e científicas que buscam promover e liderar a produção e a difusão de conhecimento e informação sobre a região podem tornar-se espaços de disputas em torno dos significados de América Latina e dos projetos políticos relacionados, de modo a refletir conflitos geopolíticos mais amplos, enraizados no sistema mundial e, ao mesmo tempo, a também exercer influência sobre estratégias e modelos de integração e cooperação na região. Por outro lado, apesar da persistência de muitas diferenças e tensões internas, a LASA também pode ser identificada como uma instância estratégica para articulações Norte-Sul nas áreas das Ciências Sociais e das Humanidades.

Contudo, as perspectivas latino-americanistas que buscam elevar a América Latina ao status de "sujeito de conhecimento" também enfrentam desafios no âmbito de redes e associações lideradas por intelectuais e pesquisadores latino-americanos. Como salientam vários teóricos contemporâneos, não só na América Latina, um dos principais desafios das Ciências Sociais tem sido abrigar em seu corpo teórico a demanda pelo reconhecimento de outras perspectivas e epistemologias constituídas a partir da experiência da subalternidade ou da colonialidade. São invocadas epistemologias feministas, LGBTT, indígenas, afrodiaspóricas e outras até então desconsideradas pelo conhecimento acadêmico moderno

\footnotetext{
${ }^{19}$ De acordo com Robert Packenham (1992), cerca de $85 \%$ a 90\%, até meados da década de 1980, percentual que decaiu para cerca de $50 \%$ na atualidade.

${ }^{20}$ Para Arthuro Escobar (2006), o início da década de 2000 teria sido um divisor de águas na história da LASA, com um maior equilíbrio de poder entre as diferentes vertentes internamente, favorecido pelo contexto de redemocratização, organização da sociedade civil e a ascensão de governos progressistas e de esquerda na América Latina.
} 
ocidental como contribuições ao pensamento em torno de temas tão caros às Ciências Sociais quanto os temas da democracia, do desenvolvimento e da modernidade.

\section{Campos de produção e difusão de conhecimento e informação sobre e desde a América e latino-americanismos no Brasil}

Nos campos de produção e difusão de conhecimento e informação sobre a "América Latina", o uso destacado do termo "latino-americanismo" tem forte conotação de militância, dentro e fora das arenas acadêmico-científicas, por parte de latino-americanos sediados ou não na região, com apoio de outros, não latino-americanos. Por esta via, o termo é associado a novos paradigmas epistemológicos e agendas político-programáticas, os quais são voltados, em suma, como referido anteriormente, para a defesa das identidades e da soberania da região nos contextos mais amplos de suas inserções no sistema mundial e de suas relações com países em posições centrais e hegemônicas nesse sistema. Entretanto, esta é apenas uma das passíveis de identificação, uma vez que, como também procuramos assinalar, há expressivas variações envolvendo conceitos e projetos políticos no histórico das abordagens. Dada a diversidade de representações, narrativas e agendas envolvendo a "América Latina", empreendidas por diferentes tipos de iniciativas institucionais que constituem os campos inicialmente identificados no caso do Brasil, consideramos "latino-americanismo" uma noção que deve ser referida, em primeiro lugar, restritamente a uma perspectiva especializada sobre América Latina.

Apontamos, portanto, para o plural, "latino-americanismos", tendo em vista a variedade de representações sobre a "América Latina" no Brasil, a exemplo do que pode ocorrer noutros países da região e noutras regiões, as quais mobilizam diferentes percepções, valores, identidades, expectativas e estratégias de ação. As representações e agendas sobre a América Latina no Brasil podem compreender maior ou menor correspondência e imbricação com outras, cunhadas noutros países (latino-americanos ou não), e em escalas regional e internacional, ou mesmo por iniciativas institucionais internacionais atuantes ou sediadas no país, a depender das estruturas, dinâmicas e fluxos de interação entre as partes, bem como das articulações e arenas em que são veiculadas e compartilhadas. 
Por outro lado, dentre os diversos "campos de produção e difusão de conhecimento e informação sobre a 'América Latina' no Brasil", é possível identificarmos relações de concorrência e oposição, internas a cada um e nas interfaces entre eles, o que inclusive pode resultar no não-reconhecimento (ou mesmo no desconhecimento e omissão) de pares e interlocutores potenciais mais imediatos dentre os setores, instituições e atores participantes. São também fragmentadas e descontínuas as possíveis inter-relações e redes entre os campos de produção e difusão de conhecimento e informação sobre a América Latina no Brasil ${ }^{21}$.

Com base no mapeamento preliminar de um conjunto de 146 iniciativas institucionais que produzem e difundem conhecimento e informação sobre América Latina no Brasil, destacamos que a maior parte delas foi criada a partir de 2004. De 1985 a 2003 foram 21,8\% e de 2004 até o presente foram 78,2\%, identificando-se um ápice nos anos de 2011 e 2012, de modo que é factível apontar, tentativamente, algumas relações entre os processos de integração regional (e a criação de diversas iniciativas inter-estatais voltadas para a integração na região, acima indicadas) e a proliferação de iniciativas institucionais de produção e difusão de conhecimento e informação sobre a América Latina no Brasil. Foi somente a partir do início dos anos 2000 (quando se alcançou uma maior diferenciação nas proposições das iniciativas inter-estatais de integração regional, com a emergência de projetos alternativos), que se expandiram os centros, núcleos, grupos de estudo, entre outros tipos de iniciativas com foco na região. Tais iniciativas compreendem diferentes abordagens e agendas de ação sobre a América Latina, as quais podem corresponder a distintos referenciais teóricos e metodológicos e projetos políticos para a região.

Observamos primeiramente que a constituição e a organização dos "campos de produção e difusão de conhecimento e informação sobre a 'América Latina' no Brasil" correspondem a processos que envolvem tanto matrizes e vertentes teóricas, que tomam “América Latina" como unidade de análise científica, as quais se consolidam e conquistam espaços na academia, com maior ou menor teor normativo e programático, como matrizes e vertentes políticas que assumem “América Latina” como unidade de análise e de estratégia de

\footnotetext{
${ }^{21}$ Ainda são limitados o conhecimento mútuo e a interação entre centros, programas e outras diversas iniciativas institucionais voltadas para os estudos sobre a região no Brasil, algo que, conforme observou Paulo Henrique Martins, presidente da ALAS entre 2011 e 2013, também se reflete no desconhecimento de cientistas sociais e sociólogos brasileiros acerca da ALAS e da produção sociológica latino-americana no país (Barros, 2011). Mais recentemente, José Vicente Tavares (2015), presidente da ALAS de 2005 a 2007, reafirma tal problema ao se referir também ao diálogo entre Brasil e outros países latino-americanos, observando restrita referência de autores hispano-americanos na Sociologia desenvolvida no Brasil.
} 
ação política, as quais também são, em alguma medida, apoiadas em instâncias e recursos governamentais e não-governamentais.

À luz dos dados empíricos preliminares, os “campos de produção e difusão de conhecimento e informação sobre a 'América Latina' no Brasil” são inicialmente classificados por escopo, ou seja, em termos de área e forma de produção de conhecimento e informação, compreendendo três categorias (parcialmente inter-relacionadas), a saber: i. Campos acadêmico-científicos, os predominantes, que envolvem muitas e diversas áreas, além das Ciências Sociais, ii. Campos promotores de outras formas de saber, não científicas, destacandose o artístico-cultural, o religioso e o da militância sócio-política, iii. Campos de assessoria especializada e lobby político, que apresentam uma variedade de formatos institucionais e de agendas, com iniciativas identificadas como think tanks ou de caráter mais operacional, voltadas para a implementação de projetos, prestação de serviços de consultoria e assessoria técnica especializada.

Quanto à natureza, ao tipo e ao grau de "institucionalidade", as "iniciativas institucionais" produtoras e difusoras de conhecimento e informação sobre a América Latina no Brasil revelam, igualmente, uma rica e complexa diversidade. "Iniciativa institucional" é aqui referida precisamente para dar ênfase a um gradiente de níveis variados de institucionalidade. Os dados preliminares mostram que algumas iniciativas são maiores e/ou mais consolidadas institucionalmente, outras têm em si baixa institucionalidade, a despeito de sua extensão, e outras ainda operam no limite da informalidade, em termos jurídicoinstitucionais. Ainda que predominem as iniciativas de natureza pública e de caráter acadêmicocientífico, há importantes iniciativas de caráter religioso, político ou artístico-cultural que atuam na formulação e divulgação de significados e interpretações sobre América Latina no país.

\section{Mapeamento preliminar das iniciativas institucionais no caso brasileiro}

Na seleção das iniciativas institucionais, por meio de ferramentas de busca em inúmeros portais na internet, optamos primeiramente por aquelas que apresentam "América Latina", "América Latina e Caribe", "Américas" e outros termos relacionados no nome (como latinoamericano/a, americano; sub-regiões, como "Cone Sul” e "América Platina”, e organização 
internacional voltada para a "integração", ex. "Mercosul”). Contudo, foram já incluídas iniciativas sem "América Latina" (ou correlato) no nome da iniciativa, por indicarem explicitamente "América Latina", como questão ou uma das questões centrais em suas missões e atividades ${ }^{22}$. Outro critério adotado para a seleção de nosso objeto diz respeito ao estado de funcionamento das iniciativas institucionais, de modo a priorizar as que se encontram em atividade no presente, ainda que possam apresentar descontinuidade ao longo de suas trajetórias - no entanto, sem desconhecer a relevância de iniciativas institucionais já desativadas dentre os antecedentes históricos mais relevantes dos campos.

Procedimento semelhante foi adotado no levantamento dos tipos de iniciativa institucional envolvendo "América Latina" (ou correlatos) no Brasil, com base em termos previamente definidos, de maneira independente e combinada ${ }^{23}$. Ademais, a fim de evitar sobreposições e consequente distorção de dados ou a excessiva amplificação dos dados quantitativos e, ao mesmo tempo, dar maior visibilidade aos graus de capilaridade nos campos e destacar as iniciativas institucionais que constituem novos focos de abordagem sobre "América Latina", inseridas em hierarquias institucionais previamente existentes sem tal perspectiva, foram priorizadas na seleção aquelas iniciativas que, além de apresentarem no nome o termo "América Latina" (e outros correlatos), se encontram em posição superior nas hierarquias institucionais em que estão inseridas. Nesse sentido, identificamos como parte de uma mesma iniciativa institucional todas as atividades (tais como programas de pós-graduação, revistas, laboratórios e/ou grupos de pesquisa) compreendidas em um centro, instituto, faculdade, universidade ou outro tipo de arranjo institucional com enfoque sobre a América Latina. Assim, além de evitarmos a repetição indevida de atividades compreendidas na mesma iniciativa institucional, também podemos destacar aquelas cujo enfoque é a "América Latina", ainda que não estejam inseridas em instituições com abordagem sobre a região, o que resulta em grande relevância para o maior destaque de muitas e diversas iniciativas mais dispersas, porém bastante capilarizadas e com potencial de (a depender de uma série de fatores condicionados por estratégias de políticas e recursos e redes de cooperação e associação profissional) contribuir para a ampliação da perspectiva latino-americanista nas hierarquias

\footnotetext{
${ }^{22} \mathrm{Na}$ segunda fase da pesquisa, centrada em grande parte em trabalho de campo, com o suporte da Fundação de Apoio à Pesquisa do Distrito Federal (FAP-DF), é prevista a inclusão de outras iniciativas que apresentam foco sobre a América Latina e Caribe em suas missões e objetivos, mas sem referência a estes no nome.

${ }^{23}$ Como exemplos, "centro"; "núcleo"; "instituto"; "fundação"; "casa"; "revista", "pesquisa"; "estudos"; "laboratório"; "observatório"; "rede"; "comunidade"; "sociedade"; "associação"; "fórum"; "escola"; "programa"; "frente, "aliança", "campanha" e "plataforma".
} 
institucionais em que se encontram inseridas ou associadas. Nesse caso, destacam-se, por exemplo, os grupos de pesquisa registrados no CNPq com foco na América Latina e que estão vinculados a departamentos disciplinares (de Sociologia e diversos outros, de outras áreas de conhecimento, inclusive com maior peso) ou a diversos arranjos institucionais que não apresentam perspectiva regionalista.

Tal procedimento nos permitiu, ademais, identificar outras iniciativas que têm "América Latina" no nome (ou correlato), mas que não assumem efetivamente a região como foco de suas atividades $^{24}$. Embora não integrem o conjunto de iniciativas que é objeto central da pesquisa em causa, estes casos são considerados à parte, compreendendo interessantes indicadores do crescimento do apelo no uso de "América Latina" (ou termo correlato) como estratégia de marketing da iniciativa em questão, a fim de potencializar o seu reconhecimento ou para ampliar o alcance do público-alvo almejado. Ao mesmo tempo, vale salientar que, conforme verificamos, são poucas as iniciativas que levam "Caribe" ou país caribenho como termos no nome (apenas 6 das 146 iniciativas institucionais mapeadas). Em princípio, isso não significa que o Caribe não esteja contemplado na produção do conhecimento e informação daquelas iniciativas por falta de menção expressa nos seus nomes, o que, de todo modo, pode ser indicativo da relativa marginalidade dessa região e respectivos países nos campos constituídos.

Os critérios supracitados resultaram no primeiro conjunto de 146 iniciativas institucionais, conforme referido, cujas características quanto à natureza (pública ou privada), os diferentes formatos, tipos e níveis de institucionalidade; as vinculações políticoadministrativas e institucionais; as subáreas de conhecimento e grandes áreas de concentração, e a distribuição pelo território brasileiro, por estado e região, passamos a descrever a seguir.

Primeiramente, merece destaque o fato de que, apesar da diversidade de tipos de iniciativas institucionais - as quais apresentam diferentes graus de institucionalidade e formatos institucionais (15 tipos, ao todo) - a grande maioria consiste em grupos de pesquisa registrados no diretório do $\mathrm{CNPq}$ (67,8\%). Dentre o conjunto restante das iniciativas, os principais tipos, em termos percentuais, são primeiramente os "centros" $(6,8 \%)$, seguidos pelos "institutos" $(5,4 \%)$ e os "núcleos" (4,1\%). Em menor número estão: "casa de cultura" (3,4\%); “observatório" $(2,7 \%)$; "revistas" $(2,1 \%)$; "laboratório" $(2,1 \%)$; "programa de pós-graduação"

\footnotetext{
${ }^{24}$ Por exemplo, Faculdade de Tecnologia América do Sul, Faculdade de Tecnologia Latino Americana de Anápolis (FLA); Faculdade Latino-Americana de Educação (FLATED/FUGESP); Faculdade Latino-Americana de Teologia Integral (FLAM); Instituto Latino-Americano de Direito Social (IDS) e Instituto de Educação Superior Latino Americano (IESLA).
} 
$(1,4 \%)$; "universidade" (0,7\%); "rede" (0,7\%); "fundação" (0,7\%); "faculdade" $(0,7 \%)$; "campanha" $(0,7 \%)$ e "agência de informação" $(0,7 \%)$.

A maior parte das iniciativas selecionadas está ligada a instituições acadêmicas brasileiras, sendo que as universidades públicas (federais e estaduais) prevalecem dentre as instituições que abrigam as iniciativas dedicadas à produção e difusão do conhecimento e informação sobre a América Latina. Some-se a isso o fato de que as iniciativas com "autonomia jurídica institucional" apresentam em sua missão e programas de atividades diversas formas de colaboração e parcerias com outras universidades e algumas de suas respectivas unidades, o que amplifica ainda mais a relevância das universidades brasileiras nos "campos" delimitados pela pesquisa. O número significativo de iniciativas abrigadas em instituições acadêmicas e de pesquisa (universidades, faculdades, institutos, fundações) e o grande percentual dos grupos de pesquisa/CNPq são indicadores do quão estratégico é a pesquisa no Brasil para a produção e difusão de conhecimento e informação sobre América Latina - e do quanto esta relevante produção pode estar ameaçada com os cortes orçamentários em curso.

Há ainda que se destacar que o conjunto selecionado é predominantemente formado por iniciativas institucionais públicas, $82 \%$ do total, com apenas $18 \%$ de iniciativas vinculadas às instituições privadas de diversos tipos. Do total, 13 das iniciativas, públicas e privadas também se constituem com autonomia jurídica institucional (1 pública e 12 privadas). Em natureza "privada" (empresarial e "sem fins lucrativos"), os tipos compreendidos são os seguintes: i. empresa, ii. fundação, iii. associação civil; iv. organização social de interesse público, v. campanha, e vi. rede.

O conjunto das 146 iniciativas está distribuído por 19 estados da federação e o Distrito Federal. Dentre estes, os principais, na ordem decrescente, são: $1^{\circ}$ São Paulo, $2^{\circ}$ Rio de Janeiro, $3^{\circ}$ Rio Grande do Sul, $4^{\circ}$ Pernambuco e Minas Gerais, $5^{\circ}$ Santa Catarina, $6^{\circ}$ Distrito Federal. Já os estados com menor incidência são: Rondônia, Rio Grande do Norte, Piauí, Maranhão, Ceará e Alagoas, cada um igualmente com $0,7 \%$ do total. Temos, portanto, que a distribuição por região compreende, em ordem decrescente: $43 \%$ na região sudeste, seguida por $25 \%$ na região sul, $16 \%$ na região nordeste, $13 \%$ na região centro-oeste e $3 \%$ na região norte. Esses percentuais confirmam a concentração da produção do conhecimento sobre a América Latina nas regiões sul e sudeste - que juntas abrigam $68 \%$, das iniciativas selecionadas, relegando as regiões norte e centro-oeste a uma condição mais marginal. 
No tocante à distribuição total por área de conhecimento (em conformidade com a classificação do $\mathrm{CNPq}$ ) observa-se a predominância de iniciativas nas áreas de Ciências Humanas e Ciências Sociais Aplicadas, da seguinte forma, em ordem decrescente: $43,8 \%$ em Ciências Humanas, 21,9\% em Ciências Sociais Aplicadas, 18,5\% em Linguística, Letras e Artes e 13,7\% em Multidisciplinar ${ }^{25}$. Engenharias, Relações Internacionais e Ciências da Saúde apresentam cada um $0,7 \%$. Interessante observar a situação marginal do conhecimento sobre América Latina produzido na área de Relações Internacionais, na qual prevalecem os estudos de área ou região, sugerindo que a região "América Latina" não é priorizada dentre as demais regiões, a despeito do papel regional estratégico do Brasil. Por sua vez, a distribuição total por subárea/disciplina específica aponta em ordem decrescente: 17,1\% História, 14\% Letras; 8,9\% Ciência Política, 6,8\% Direito e Comunicação (cada uma); 4,1\% Sociologia, Ciências Sociais e Educação (cada uma), 3,4\% Artes e Serviço Social (cada uma), 1,4\% Administração. As demais disciplinas aparecem individualmente com $0,7 \%$.

\section{Considerações finais e perspectivas de seguimento}

À luz das questões teóricas abordadas, referentes às relações entre as representações sobre América Latina e contextos históricos e geopolíticos específicos, e à inextricabilidade entre a produção do conhecimento sobre e desde a América Latina e os processos de regionalização e projetos de integração regional, destacamos aspectos do nosso objeto de pesquisa (as 146 iniciativas institucionais de produção e difusão de conhecimento e informação sobre a América Latina no Brasil) que nos permitem sugerir preliminarmente algumas tendências e hipóteses indicativas do funcionamento deste campo e seus possíveis desdobramentos quanto às possibilidades da consolidação institucional do latino-americanismo - aqui compreendido no singular simplesmente como produção do conhecimento voltado para a América Latina - no país.

Conforme se pode depreender dos dados levantados até o momento, há uma notável coincidência entre a profusão de iniciativas com enfoque na América Latina a partir dos anos

\footnotetext{
${ }^{25}$ Nota-se que o CNPq não utiliza a classificação "multidisciplinar". Designamos desta forma as iniciativas que combinam perspectivas de disciplinas diversas seja pelas temáticas ou enfoques envolvidos. Quanto aos Grupos de Estudo, é possível que o registro no Diretório CNPq seja o da unidade de vinculação institucional em que se dá a iniciativa, na falta da opção "multidisciplinar".
} 
2000, quando também o Brasil passa a ter uma participação mais ativa em processos de integração regional, pautada por uma política exterior mais empenhada em se articular com os países vizinhos ao invés de uma integração com as "Américas", como a pretendida por via da ALCA, por exemplo. Este aspecto parece reiterar a relação histórica entre o conhecimento produzido sobre e desde a América Latina, os processos políticos na região e os projetos de integração decorrentes. Como apontamos, algumas das principais contribuições para o pensamento social latino-americano se fizeram em contextos atravessados por disputas e reações a projetos concebidos para a região desde fora ou "do norte".

Ademais, vale lembrar, esse também é um período marcado por investimentos significativamente maiores nas universidades públicas, através do Programa de Reestruturação e Expansão das Universidades Federais (Reuni), instituído pelo Decreto No 6.096, de 24 de abril de 2007, cujo principal propósito era ampliar o acesso e a permanência na educação superior por meio da expansão física, acadêmica e pedagógica da rede federal de ensino superior $^{26}$. Tal fato se torna especialmente relevante, posto que a maioria das iniciativas institucionais selecionadas é abrigada por instituições públicas de ensino superior (em grande parte federais), cujas missões caracterizam-se por conjugar atividades de formação (docência), pesquisa e extensão, sendo uma dessas iniciativas, aliás, ela própria, uma universidade voltada para a integração latino-americana - a Universidade Federal da Integração Latino-Americana (UNILA).

Importante ressaltar a UNILA nesse contexto, a qual, conforme afirmou o presidente da comissão que a instituiu em 2008, Hélgio Trindade, "marca um tríplice movimento estratégico: primeiro, retoma a vocação histórica da educação superior pública no Brasil, com a expansão do sistema federal e a diversificação de seu espaço territorial. Segundo, simboliza um avanço decisivo na interiorização da educação superior que, com novas universidades (Unipampa e Fronteira Sul) tangencia as fronteiras com os demais países da América do Sul. Terceiro, voltase para a integração da América Latina através de um novo elo substantivo: a integração pelo conhecimento e a cooperação solidária entre os países do continente mais do que nunca em uma cultura de paz." (Trindade, 2008: 2; grifo nosso) ${ }^{27}$.

\footnotetext{
${ }^{26} \mathrm{http} / / /$ reuni.mec.gov.br/o-que-e-o-reuni

${ }^{27}$ https://www.unila.edu.br/sites/default/files/files/Sobre_a_Comiss\%C3\%A3o_Implanta\%C3\%A7\%C3\%A3o.pd f (acesso em 09 de outubro de 2017).
} 
Em tal direção, enfatizamos a relevância dos grupos de pesquisa registrados no diretório do CNPq dentre o conjunto de iniciativas em nosso mapeamento preliminar, o que aponta para o valor estratégico da pesquisa acadêmico-científica na produção do conhecimento sobre e desde a América Latina no Brasil. Decerto, a concentração das iniciativas institucionais dedicadas à produção e difusão de conhecimento sobre a América Latina na região no âmbito acadêmico e, em especial, nas universidades públicas, não resulta necessariamente na predominância de um conhecimento de caráter "militante" ou mais afinado com o chamado pensamento crítico latino-americano, voltado para a promoção de perspectivas contrahegemônicas e anti-sistêmicas ou comprometido com projetos mais autônomos de integração latino-americana. Trata-se, na verdade, de uma produção variada, promovida a partir de diferentes perspectivas disciplinares (ainda que predominantemente nas áreas de ciências humanas e sociais) e ancoradas em instituições onde prevalecem os financiamentos públicos, por meio de editais abertos.

Com base nos dados até então sistematizados, tampouco podemos afirmar que os grupos de pesquisa sejam necessariamente engajados em uma ampla rede de difusão e circulação de conhecimento, a ponto de efetivamente influenciarem agendas acadêmicas ou políticas de integração (ou de outra natureza) para a região, na região e fora dela, o que no momento nos impede de fazer inferências quanto ao seu real poder de veiculação de conhecimento desde e para a América Latina. De todo modo, é nessa instância principalmente que identificamos a maior parte da produção sobre a América Latina no Brasil, o que, novamente, aponta para a área da pesquisa acadêmica como importante protagonista no processo.

A evidente concentração em iniciativas institucionais de caráter acadêmico de natureza pública é indicativa de que os cortes recentes de recursos para as universidades públicas e por parte das agências de fomento à pesquisa podem significar uma grande e preocupante ameaça à consolidação e continuidade da produção de conhecimento com enfoque regional. Como salienta Borón (2005), a considerável redução de investimento público nas instituições de ensino e pesquisa mostra-se altamente desfavorável às pesquisas comparativas e internacionais, de largo alcance e perspectiva macro, sob as quais se gestou o pensamento crítico latinoamericano. Ao contrário, o que se anuncia é uma política de cortes que dá margem à prevalência de pesquisas financiadas por fontes privadas ou gestadas segundo um modelo de consultoria, cujas abordagens tendem a gerar resultados parciais e fragmentados que limitam, além de tudo, a compreensão mais sistêmica e estrutural de processos que atingem a região. Ainda, o fato da 
maioria esmagadora da produção do conhecimento sobre América Latina no Brasil se dar no âmbito dos grupos de pesquisa sugere o baixo grau de consolidação institucional dessas iniciativas, as quais se veem ainda mais vulneráveis e sujeitas a descontinuidades em situações de cortes de recursos do financiamento público.

Uma pergunta que prossegue para nós, enquanto partícipes do objeto de estudo, é se podemos pensar a nós próprios num campo de interesses conflitantes, no sentido bourdieusiano, justamente numa conjuntura em que defender a autonomia da ciência é menos acusá-la de qualquer isolacionismo e mais se preocupar com sua vitalidade, quando o cenário atual a submete a vários ataques ideológicos, tendo em vista seu enfraquecimento enquanto postuladora de sentidos do mundo.

Curiosamente, como sugere Adélia Miglievich-Ribeiro (2013), somos obrigadas a recorrer a Robert King Merton (1985) e a sua ênfase na "comunidade científica", sem, por isso, concordarmos com a ideia de consenso em seu interior, mas apenas para imaginar que a capacidade de criar "blindagens" entre a produção intelectual acadêmica e as forças do mercado e do capital é uma vantagem para a ciência. Ainda assim, todavia, não resolvemos uma outra dificuldade que abordamos ao longo do artigo, a de vislumbrar o efetivo impacto dos grupos de pesquisa no Brasil que se dedicam a pensar a América Latina de uma perspectiva antihegemônica, na promoção de resistências geopolíticas. Para tanto, precisaremos seguir explorando o entrelaçamento entre seus atores e a luta política.

Deste modo, em que pese a ênfase de Bourdieu nas disputas internas ao campo, pesquisar os "campos de força" na produção e difusão de conhecimento e informação sobre a América Latina e o Caribe implica fortalecê-lo e expandi-lo. É importante considerar que fragilizar o "capital científico" - conforme temos testemunhado mais recentemente - não parece ser uma boa política para a ciência. Ao contrário, é o capital científico destes campos que se espera ver incentivado para impactar as desejáveis mudanças em prol de processos e instâncias de cooperação e integração regional mais justos e solidários, que também compreendam dimensões sócio-culturais e científicas na busca da auto-determinação das sociedades na região. 


\section{Referencias bibliográficas}

ARDAO, Arthuro. (1986). "Panamericanismo y latinoamericansmo". In: ZEA, Leopoldo (Coordinador). América Latina en sus ideas. SigloVeintiuno Editores y UNESCO, México. . (1980). Genesis de laidea y elnombre de America Latina. Caracas, Venezuela: Centro de Estudios Latinoamericanos Rómulo Gallegas, 1980.

BARROS, Flávia Lessa de. (2011).. “A Sociologia latino-americana entre os desafios da descolonização planetária e a reconstrução da utopia democrática - Uma reflexão a partir da ALAS". Entrevista com Paulo Henrique Martins. REALIS - Revista de Estudos AntiUtilitaristas e PósColoniais. Vol. 1, $\mathrm{n}^{\mathrm{o}} 1$.

BERGER, Peter; LUCKMANN, Thomas. (1985). A construção social da realidade. Rio de Janeiro: Editora Vozes.

BETHELL, Leslie. (2009). "O Brasil e a ideia de América Latina em perspectiva histórica" IN: Est. Hist., Rio de Janeiro, vol. 22, n. 44, p. 289-321, julho-dezembro.

BIELSCHOWSKY, Ricardo (2011). "Prefácio: Prebisch e Furtado" In: Gurrieri, A. (org). Raul Prebisch: O manifesto Latino-Americano e outros ensaios. Rio de Janeiro: Contraponto: Centro Intenracional Celso Furtado.

BORÓN, Atilio. (2005). "Las Ciencias Sociales en la era neoliberal. Entre la academia y el pensamiento crítico". Conferência Magistral no XXV Congresso da ALAS, Porto Alegre RS, 22-26 de agosto. Em:

http://bibliotecavirtual.clacso.org.ar/ar/libros/panama/cela/tareas/tar122/03boron.htmlCon sultado em 20/02/2017

. (2006) "Las ciencias sociales en la era neoliberal: entre la academia y el pensamiento crítico". In: Tareas no. 122. CELA, Centro de Estudios Latinoamericanos "Justo Arosemena". Enero-Abril.

.(2003). Estado, capitalismo y democracia na América Latina. Buenos Aires, CLACSO, 2003. Em: http://biblioteca.clacso.edu.ar/gsdl/collect/clacso/index/assoc/D775.dir/estado2.pdf. (2002) . Império, imperialismo (Una leitura crítica de Michael Hardt y Antonio Negri). Buenos Aires-Argentina: CLACSO.

BOURDIEU, Pierre. (2004). Os usos sociais da ciência. Por uma sociologia clínica do campo científico. SP: Ed. Unesp.

CARCANHOLO, Marcelo Dias; SALUDJIAN, Alexis (2013). "Os efeitos da integração sulamericana sob a influencia neoliberal”. In: FLORES, Consuelo Silva; MARTINS, Carlos Eduardo. (Org.). Nuevos Escenarios para la Integración en América Latina. 1ed.Santiago - Buenos Aires: Editorial ARCIS - CLACSO, v. 1, p. 215-239.

CRUZ, Sebastião Velasquez. (2007). Trajetórias: capitalismo neoliberal e reformas econômicas nos países da periferia. São Paulo: Unesp.

ESCOBAR, Arthuro. (2006). "Revisioning Latin American and Caribbean Studies: A geopolitics of Knowledge approach". Forum. Latin American Studies Association. Volume XXXVII Issue 2, Spring 2006, pp.11-13. 
FERES Jr., João. (2005). A história do conceito de 'LatinAmerica' nos Estados Unidos. Bauru, SP: EDUSC.

FOUCAULT, Michel. (1980). Power/Knowledge: selected writings. Edited by Colin Gordon, New York: Pantheon Books.

Vintage Books.

(1978). The history of sexuality: an introduction. Vol. 1, New York:

GENTILI, Pablo; SAFORCADA, Fernanda. (2010). “A expansão da Pós-Graduação em Ciências Sociais, desigualdade regional, competência e mercantilização na América Latina". Série Cadernos FLACSO N2, outubro. Em: http://flacso.org.br/files/2014/12/N2Gentili e Saforcada-Portugues.pdf. (Consultaem 19/02/2017)

HETTNE, Björn. (1990). "Development thinking and the three worlds.Towards an international political economy of development".New York: LongmanScientific e Technical.

IANNI, Otávio. (2002). Enigmas do Pensamento latino-americano. Instituto de Estudos Avançados da Universidade de São Paulo. Em: www.iea.usp.br/artigos (Consulta em 20/02/2017).

. (1988). “A questão nacional na América Latina”. Estudos Avançados. Vol. 2, Nº , São Paulo, jan/mar.

LANDER, Edgardo (2006). Neoliberalismo, sociedad civil y democracia: ensayos sobre América Latina y Venezuela. Universidad Central de Venezuela. Consejo de Desarollo Científico y Humanístico.

LOPEZ-SEGRERA, Francisco (2000). “Abrir, impensar y redimensionar las ciencias sociales de América Latina y el Caribe. Es posible uma ciencia social no eurocêntricaem nuestra región?” In: LANDER, Edgardo. (Comp). La colonialidaded del saber: eurocentrismo y ciencias sociales. Perspectivas latinoamericanas. Buenos Aires: CLACSO, Julio de 2000 .

MARINI, Rui Mauro (1992). América Latina: Dependência e Integração. Ed. Brasil Urgente.

(1993)."Las raíces del pensamiento latinoamericano" (Ponencia). Centro

de Estudios Miguel Enrique. Arquivo Chile - História Político Social-Movimento Popular. Em:

http://www.archivochile.com/Ideas_Autores/maurinirm/03al/maurini_al00014.pdf (Consulta em 05/03/2017)

MARTINS, Carlos Eduardo. Globalização, dependencia e neoliberalismo na América Latina. Rio de Janeiro-RJ: Boitempo, 2011. . (2004). Dependência e desenvolvimento no moderno sistema-mundo.

Buenos Aires: CLACSO. Em:

http://biblioteca.clacso.edu.ar/clacso/becas/20140310040949/DaRosaMartins.pdf. (Consulta em 10/02/2017).

MARTINS DE ALBUQUERQUE, Paulo Henrique Novaes (2012). La decolonialidad de América Latina y la heterotopia de una comunidad de destino solidaria. - Buenos Aires: Fundación CICCUS; Estudios Sociológicos Editora, 1ª ed. E-Book.

MERTON, Robert K.(1985). La sociología de La ciencia. Madri, Alianza Editorial, 2 vols. 
MIGLIEVICH-RIBEIRO, Adélia M. (2013). Darcy Ribeiro e as experiências de renovação universitária no Brasil, Uruguai e Peru nos anos 1960 e 1970: conexões com o debate contemporâneo da modernidade-colonialidade". Relatório Científico. Programa PDS 2013-1, p. 1-52.

MIGNOLO, Walter (2005). La idea de America Latina. La herida colonial e la opción decolonial. Barcelona: Gedisa.

PACKENHAM, Robert. (1998).The Dependency Movement: Scholarship and Politics in Development Studies. USA, Havard University Press, 1998.

PHELAN, John Leddy. (1993). El origen de la idea de Latinoamérica. In: ZEA, Leopoldo (Comp.). Fuentes de la cultura latinoamericana. Tomo I. México: Fondo de Cultura Económica.

RAFAEL, Vicente L (1994). "The Cultures of AreaStudies". Social Text 41. pp. 91-111

RIBEIRO, Darcy. (2002) “La nación latinoamericana”. (Nueva Sociedad No 62 Septiembre/ Octubre 1982). 30 Años de Nueva Sociedad. Nueva Sociedad No 180-181, JulAgo/Septiembre-Octobre.

RODRIGUEZ, Octavio (2009). "O neo-estruturalismo latino-americano e a agenda do desenvolvimento". O estruturalismo latino-americano. Rio de Janeiro: Civilização Brasileira.

SALUDJIAN, Aléxis. (2004). Hacia outra integración sudamericana. Críticas al Mercosur neoliberal. Bueno Aires: Libros de Zorzal.

SIERRA, Gerônimo de. (2015). "América Latina. Una y diversa”. In: BIALAKOWSKY, Alberto; CATHALIFAUD, Marcelo Arnold; MARTINS, Paulo Henrique (Compiladores). El pensamiento latinoamericano. Sociedad y Sociologia. Ciudad Autónoma de Buenos Aires: Teseo.

TAVARES, José Vicente. (2015). "La internacionalización de la sociologia crítica y La superación de La colonialidad”. In: BIALAKOWSKY, Alberto; CATHALIFAUD, Marcelo Arnold; MARTINS, Paulo Henrique (Compiladores). El pensamiento latinoamericano. Sociedad y Sociologia. Ciudad Autónoma de Buenos Aires: Teseo.

WALLERSTEIN, Immanuel (2004). The world-system analysis. An introduction. Durham/London.

(1995). After Liberalism. New York: City University of New York Press.

(1984). The politics of world-economy. The states, the movements and the civilizations. Cambridge, 1984.

WALLERSTEIN, Immanuel et. alli. (1996). Para abrir as Ciências Sociais. Comissão Gulbenkian. SP: Ed. Cortez, pp. 13-53.

ZEA, Leopoldo. (1992). “De quem é o mundo”. Nossa América, Fundação Memorial da América Latina março-abril. p.50-55.

ZURBRIGGEN, Cristina (2007). "La 'falácia tecnocrática' y la reforma del Estado. A 10 anos del Informe del Banco Mundial”. Nueva Sociedad No 210 Julio-Agosto.

\section{Recebido em: 10/09/2017. Aceito em: 17/10/2017}




\section{Apêndice}

\begin{tabular}{|c|c|}
\hline \multicolumn{2}{|l|}{ Iniciativas institucionais por ano de criação } \\
\hline Casa Latino-Americana (CASLA) & 1985 \\
\hline Instituto Políticas Alternativas para o Cone Sul (PACS) & 1986 \\
\hline Casa da Cultura da América Latina (CAL) & 1987 \\
\hline Centro de Pesquisa e Pós-Graduação sobre as Américas (CEPPAC) & 1987 \\
\hline Instituto Fernand Braudel de Economia Mundial & 1987 \\
\hline Programa de Pós-Graduação Interunidades em Integração da América Latina (PROLAM) & 1988 \\
\hline Memorial da América Latina & 1989 \\
\hline Faculdade Latino-Americana de Ciências Sociais (FLACSO - BRASIL) & 1990 \\
\hline Núcleo de Estudos Arte, Cultura e Sociedade na América Latina e Caribe (MUSA) & 1990 \\
\hline Grupo de Pesquisa A Mulher Cidadã na América Latina & 1992 \\
\hline Programa de Mestrado em Integração Latino-Americana (MILA) & 1993 \\
\hline Grupo de Pesquisa Escravidão, População e Economia nas Américas e na África, Séculos XVI-XIX & 1994 \\
\hline Instituto Latino-Americano de Estudos Avançados (ILEA) & 1994 \\
\hline Centro de Integração do Mercosul & 1995 \\
\hline Fundação Bienal de Artes Visuais do MERCOSUL & 1995 \\
\hline Grupo de Pesquisa Música Étnica e Popular (Brasil/América Latina) & 1995 \\
\hline Grupo de Pesquisa Núcleo de Estudos Latino-Americanos - NELAM & 1995 \\
\hline Grupo de Pesquisa Questões de Hibridação Literária nas Américas & 1995 \\
\hline Instituto Imersão Latina (IMEL) & 1995 \\
\hline Centro de Estudos Latino-Americanos sobre Cultura e Comunicação (CELACC) & 1996 \\
\hline Grupo de Pesquisa Programa de Estudos e Pesquisas em História da América - PEPHAM & 1996 \\
\hline Grupo de Pesquisa Rede das Américas e Caribe para Tolerância e Solidariedade (antiga Rede UNESCO) & 1997 \\
\hline Grupo de Pesquisa A Recepção Crítica de Darcy Ribeiro na América Latina & 1998 \\
\hline $\begin{array}{l}\text { Grupo de Pesquisa Capital Social e Desenvolvimento Sustentável na América Latina: Cultura Política, Cidadania e } \\
\text { Qualidade Democrática }\end{array}$ & 1999 \\
\hline Grupo de Pesquisa Literatura Comparada na América Latina: Perspectivas Teórico-Críticas & 1999 \\
\hline Núcleo de Estudos para América Latina (NEAL) & 1999 \\
\hline Agencia de Información Fray Tito para América Latina & 2000 \\
\hline Campanha Latino-americana pelo Direito à Educação (CLADE) & 2000 \\
\hline $\begin{array}{l}\text { Grupo de Pesquisa A gestação da memória, da literatura, da crítica no exílio e outras interlocuções latino- } \\
\text { americanas }\end{array}$ & 2002 \\
\hline Observatório Latino-Americano de Políticas Educacionais (OLPEd) & 2002 \\
\hline Grupo de Pesquisa Cinema Latino-americano & 2003 \\
\hline Centro de Estudos de História da América Latina (CEHA) & 2004 \\
\hline Grupo de Estudos de Política da América Latina - GEPAL & 2004 \\
\hline Grupo de Estudos em História Sociocultural da América da Latina - GEHSCAL & 2004 \\
\hline Grupo de Pesquisa Estudos Coloniais Latino-americanos & 2004 \\
\hline Grupo de Pesquisa Identidades Americanas & 2004 \\
\hline Grupo de Pesquisa Nações e Nacionalismo nas Américas & 2004 \\
\hline Grupo de Pesquisa Pensamento Comunicacional Latino-americano & 2004 \\
\hline Grupo de Pesquisa América Latina: Representações Literárias Contemporâneas & 2005 \\
\hline Grupo de Pesquisa O Brasil e as Américas & 2005 \\
\hline Grupo de Pesquisa Reformas e Políticas Educacionais na América Latina & 2005 \\
\hline Grupo de Pesquisa Representações Históricas nas Literaturas das Américas & 2005 \\
\hline Grupo de Pesquisa Sociedades Escravistas nas Américas & 2005 \\
\hline Núcleo de Estudos de Teoria Social e América Latina (NETSAL) & 2005 \\
\hline Grupo de Estudos e Pesquisa em Políticas Públicas e Gestão da Educação na América Latina e Caribe - PGEALC & 2006 \\
\hline Grupo de Pesquisa Estado e Capitalismo na América Latina & 2006 \\
\hline $\begin{array}{l}\text { Grupo de Pesquisa Pensamento Social e Realidade Brasileira na América Latina e Centro de Estudos Octávio } \\
\text { Ianni }\end{array}$ & 2006 \\
\hline Grupo de Pesquisa Religião e Periferia Urbana na América Latina - REPAL & 2006 \\
\hline Instituto de Estudos Latino-americanos (IELA) & 2006 \\
\hline Núcleo de Estudos dos Partidos Políticos Latino-Americanos (NEPPLA) & 2006 \\
\hline Casa da América Latina & 2007 \\
\hline Grupo de Pesquisa Desigualdade Social e Pobreza na América Latina e no Leste Asiático & 2007 \\
\hline Grupo de Pesquisa José Veríssimo e o Pensamento Educacional Latino-americano & 2007 \\
\hline Grupo de Pesquisa Literatura, Arte, Cultura, História e Sociedade na Amazônia, Brasil e América Latina & 2007 \\
\hline Grupo de Pesquisa Movimentos Sociais, Educação e Diversidade na América Latina & 2007 \\
\hline Instituto Cultural de Integração da América Latina - Dom Oscar Arnulfo Romero e Gáldamez (ICIAL) & 2007 \\
\hline Instituto para o Desenvolvimento de Energias Alternativas na América Latina (IDEAL) & 2007 \\
\hline Observatório dos Movimentos Sociais na América Latina & 2007 \\
\hline Revista Gestão Universitária na América Latina (GUAL) & 2007 \\
\hline Universidade Federal da Integração Latino-Americana (UNILA) & 2007 \\
\hline Grupo de Estudos de História do Jornalismo na América Latina & 2008 \\
\hline Grupo de Estudos e Pesquisa Trabalho e Política Social na América Latin & 2008 \\
\hline
\end{tabular}


Grupo de Pesquisa América Latina e Marx: Movimentos Sociais, Partidos, Estado e Cultura $\quad 2008$

\begin{tabular}{|l|l}
\hline Grupo de Pesquisa América Latina: Política, Sociedade e Transformações Globais & 2008 \\
\hline
\end{tabular}

\begin{tabular}{|l|l}
\hline Grupo de Pesquisa América Platina: Poder, Ideias e Relações regionais & 2008
\end{tabular}

\begin{tabular}{|l|l}
\hline Grupo de Pesquisa Lazer, Brasil \& América Latina - OTIUM & 2008 \\
\hline
\end{tabular}

\begin{tabular}{|l|l}
\hline Grupo de Pesquisa Núcleo de Estudos das Américas & 2008 \\
\hline Gupo
\end{tabular}

\begin{tabular}{|c|c}
\hline Grupo de Pesquisa Afro-Latino-América: Estudos Comparados & 2009 \\
\hline
\end{tabular}

\begin{tabular}{|l|l}
\hline Grupo de Pesquisa Jesuítas nas Américas & 2009 \\
\hline
\end{tabular}

\begin{tabular}{|l|l}
\hline Grupo de Pesquisa Questão Social e Direitos Humanos na América Latina & 2009 \\
\hline
\end{tabular}

Grupo de Pesquisa Temáticas, Narrativas e Representações Árabes, Africanas, Asiáticas e Sul-americanas e de $\quad 2009$

Comunidades Diaspóricas

Grupo de Pesquisa Tradução e Interculturalidade em Narrativas na América Latina

Grupo de Pesquisa Trânsitos nas Américas: viagens e viajantes (séculos XIX e XX)

Grupo de Estudos e Pesquisas da América Latina Contemporânea - GEPALC

Grupo de Estudos e Pesquisas Práxis sobre Estado e Luta de Chsses na Aḿ́ica I

\begin{tabular}{|l|l}
\hline Grupo de Pesquisa Cinema Latino-americano e Vanguardas Artísticas - Diálogos entre Construção, Expressão e & 2010 \\
\hline
\end{tabular}

\begin{tabular}{|l|l} 
Grupo de Pesquisa Estudos sobre Política, Idéias e Fronteiras Americanas - EPIFAN & 2010
\end{tabular}

\begin{tabular}{|l|l}
\hline Grupo de Pesquisa Observatório do Movimento pela Tecnologia Social na América Latina & 2010 \\
\hline
\end{tabular}

\begin{tabular}{|l|l}
\hline Grupo de Pesquisa Pensamento Social Latino-americano & 2010
\end{tabular}

\begin{tabular}{|l|l}
\hline Grupo de Pesquisa Políticas Sociais no Brasil e na América Latina & 2010 \\
\hline
\end{tabular}

\begin{tabular}{|l|l}
\hline Laboratório de Estudos da América Latina (LEAL) & 2010
\end{tabular}

\begin{tabular}{|l|l}
\hline Laboratório de Estudos sobre Hegemonia e Contra-Hegemonia & 2010
\end{tabular}

\begin{tabular}{|c|c}
\hline Centro de Pesquisa em Comportamento Político, Opinião Pública e Eleições na América Latina & 2011 \\
\hline
\end{tabular}

\begin{tabular}{|l|l}
\hline Centro Latino-americano de Estudos em Cultura & 2011 \\
\hline Cen
\end{tabular}

\begin{tabular}{|l|l}
\hline Centro Latino-americano de Políticas Públicas (CLPP) & 2011 \\
\hline
\end{tabular}

\begin{tabular}{|l|l}
\hline Grupo de Estudos de Pensamento Latino-americano & 2011
\end{tabular}

\begin{tabular}{|l|l}
\hline Grupo de Pesquisa A Proteção do Meio ambiente no Novo Constitucionalismo Latino Americano & 2011
\end{tabular}

\begin{tabular}{|c|c}
\hline Grupo de Pesquisa e Extensão do Teatro na América Latina - PÉTALA & 2011 \\
\hline
\end{tabular}

\begin{tabular}{l|l}
\hline Grupo de Pesquisa Estudos Históricos Latino-americanos & 2011
\end{tabular}

\begin{tabular}{l|l}
\hline $\begin{array}{l}\text { Grupo de Pesquisa Laboratório de Estudos Interdisciplinares em Direito Constitucional Latino-Americano } \\
\text { (LEICLA) }\end{array}$ & 2011 \\
\hline Gupo
\end{tabular}

Grupo de Pesquisa Observatório da Radiodifusão Publica na América Latina

2011

\begin{tabular}{|l|l}
\hline Grupo de Pesquisa Processos Políticos e Políticas Públicas na América Latina & 2011 \\
\hline
\end{tabular}

\begin{tabular}{|l|l}
\hline Laboratório de Pesquisa de História das Américas & 2011 \\
\hline
\end{tabular}

\begin{tabular}{|l|l}
\hline Núcleo de Estudos e Pesquisas em América Latina e Política Comparada & 2011 \\
\hline
\end{tabular}

\begin{tabular}{|l|l}
\hline Rede Latino-Americana de Justiça de Transição (RLAJT) & 2011 \\
\hline Ret
\end{tabular}

\begin{tabular}{|l|l}
\hline Revista de Estudos Latino-americanos (ALMANAQUE) & 2011 \\
\hline
\end{tabular}

\begin{tabular}{|l|l}
\hline Centro Interdisciplinar de Estudos África-Américas (CIEAA) & 2012 \\
\hline
\end{tabular}

\begin{tabular}{|l|l}
\hline Grupo de Estudos em Literatura latinoamericana dos séculos XX e XXI & 2012 \\
\hline
\end{tabular}

\begin{tabular}{|l|l}
\hline Grupo de Pesquisa Constitucionalismo na América Latina & 2012 \\
\hline
\end{tabular}

\begin{tabular}{|l|l}
\hline Grupo de Pesquisa De-colonização e América Latina & 2012 \\
\hline Gra
\end{tabular}

\begin{tabular}{|l|l}
\hline Grupo de Pesquisa Dimensões Culturais e Políticas do Exílio Latino-americano & 2012 \\
\hline
\end{tabular}

\begin{tabular}{|l|l}
\hline Grupo de Pesquisa Formação do Professor de Espanhol em Contexto Latino-americano - PROELE & 2012 \\
\hline Gut
\end{tabular}

\begin{tabular}{|l|l}
\hline Grupo de Pesquisa Fronteiras Interamericanas: Imagens de uma Cartografia Cultural em Construção & 2012 \\
\hline
\end{tabular}

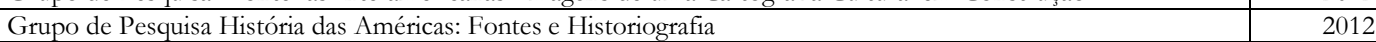

\begin{tabular}{|l|l}
\hline Grupo de Pesquisa Interculturalidade na América Latina & 2012 \\
\hline Gupo
\end{tabular}

\begin{tabular}{|l|l}
\hline Grupo de Pesquisa Jurisdição e Processos Constitucionais na América Latina: Análise Comparada & 2012 \\
\hline Gupo
\end{tabular}

\begin{tabular}{|l|l}
\hline Grupo de pesquisa Libertadores de América: Abreu e Lima e a pós-colonialidade latino-americana & 2012 \\
\hline
\end{tabular}

\begin{tabular}{|l|l}
\hline Grupo de Pesquisa Política, Estado e América Latina & 2012 \\
\hline
\end{tabular}

\begin{tabular}{|l|l}
\hline Grupo de Pesquisa Políticas Públicas e Práticas Docente em Países da Latino-américa-Brasil e Cuba & 2012 \\
\hline
\end{tabular}

\begin{tabular}{|l|l}
\hline Instituto Surear - Nosso Norte é o Sul & 2012 \\
\hline
\end{tabular}

\begin{tabular}{|l|l}
\hline Núcleo de História Econômica da Dependência Latino-Americana - HEDLA & 2012
\end{tabular}

\begin{tabular}{|l|l}
\hline Revista Latino-Americana de História & 2012 \\
\hline Cento
\end{tabular}

\begin{tabular}{|l|l}
\hline Centro de Estudos Latino-americanos & 2013 \\
\hline Circulo de Estondo
\end{tabular}

\begin{tabular}{|l|l}
\hline Círculo de Estudo em Cultura Latino-Americana (CECLAM) & 2013 \\
\hline
\end{tabular}

\begin{tabular}{|l|l}
\hline Grupo de Pesquisa Americanidades: Lugar, Diferença e VIolência & 2013 \\
\hline
\end{tabular}

\begin{tabular}{l|l}
$\begin{array}{l}\text { Grupo de Pesquisa C.A.N.E.L.A. - Cidade \& Campo: Artes e Nexos em Estudos Culturais Latino-Americanos } \\
\text { (Grupo de Pesquisa e Extensão) }\end{array}$ & 2013 \\
\hline
\end{tabular}

\begin{tabular}{|l|l} 
(Grupo de Pesquisa e Extensão) & \\
\hline Grupo de Pesquisa Cartografia do Exilio e suas Manifestações na Literatura da America Latina & 2013
\end{tabular}

\begin{tabular}{|c|c}
\hline Grupo de Pesquisa Desafios da Integração na América Latina e Caribe & 2013 \\
\hline
\end{tabular}

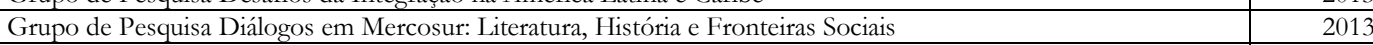

\begin{tabular}{|l|l}
\hline Grupo de Pesquisa Legado Intelectual e Produção Literária de Autoria Feminina na América Latina & 2013 \\
\hline
\end{tabular}

\begin{tabular}{|l|l}
\hline Grupo de Pesquisa Núcleo de Estudos e Pesquisas: Trabalho, Questão Social e América Latina & 2013 \\
\hline Grupo de Pesqua
\end{tabular}

\begin{tabular}{|l|l}
\hline Grupo de Pesquisa Percursos de Performatividade: Mediterrâneo, África, Américas & 2013 \\
\hline
\end{tabular}

\begin{tabular}{|l|l}
\hline Observatório do Trabalho na América Latina (OTAL) & 2013 \\
\hline Cent & 2014 \\
\hline
\end{tabular}

\begin{tabular}{|l|l}
\hline Centro de Pesquisa em História da América & 2014 \\
\hline
\end{tabular}

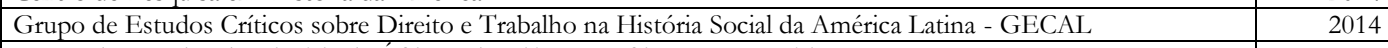

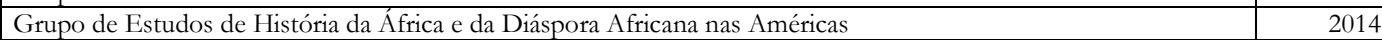

\begin{tabular}{|l|l}
\hline Grupo de Pesquisa Cinema e Audiovisual na América Latina: Economia e Estética & 2014 \\
\hline
\end{tabular}

\begin{tabular}{|l|l}
\hline Grupo de Pesquisa Laboratório de Arqueologia, Sociedade e Culturas das Américas - LASCA & 2014 \\
\hline
\end{tabular}

\begin{tabular}{|l|l}
\hline Grupo de Pesquisa Laboratório de Estudos Ibéricos e Americanos - LEIA & 2014 \\
\hline
\end{tabular} 


\begin{tabular}{|l|c|}
$\begin{array}{l}\text { Grupo de Pesquisa Observatório Latino-Americano de Indústria de Conteúdos Digitais (Transmídias e } \\
\text { Convergência Tecnológica) }\end{array}$ & 2014 \\
\hline $\begin{array}{l}\text { Grupo de Pesquisa Polêmicas Intelectuais na América Latina entre os Séculos XIX e XX: Retórica, Cultura e } \\
\text { História }\end{array}$ & 2014 \\
\hline $\begin{array}{l}\text { Grupo de Pesquisa sobre Constitucionalismo Democrático Latinoamericano: Novas Intersubjetividades e } \\
\text { Emancipação Social - MINGA }\end{array}$ & 2014 \\
\hline Grupo de Pesquisa Teoria do Estado ,Constituição e América Latina - TECAL & 2014 \\
\hline Grupo Eduardo Galeano de Estudos e Pesquisas Latino-Americanas em Comunicação Social & 2014 \\
\hline Grupo de Estudos em Literaturas Contemporâneas e Identidade Cultural na América - GELIC & 2015 \\
\hline Grupo de Pesquisa Cultura, Arquitetura e Cidade na América Latina & 2015 \\
\hline Grupo de Pesquisa História da América Contemporânea & 2015 \\
\hline Grupo de Pesquisa Laboratório Amazônico de Estudos em América Latina & 2015 \\
\hline Grupo de Pesquisa Pensamento Jurídico Crítico Latino-americano & 2015 \\
\hline Grupo de Pesquisa Violência, Infância e Juventude na América Latina & 2015 \\
\hline Instituto de Estudos da América Latina (IAL) & 2015 \\
\hline Núcleo de Estudos e Pesquisas América Latina em Movimento (NEPALM) & 2015 \\
\hline Observatório Latino-Americano de Pesquisa em Secretariado Executivo (OLASEC) & 2015 \\
\hline Grupo de Pesquisa LAméricas. Estudos e Pesquisas em História da América Colonial & 2016 \\
\hline Grupo de Pesquisa Mídia e Política: Narrativas sobre a América Latina & 2016 \\
\hline $\begin{array}{l}\text { Grupo de Pesquisa Pluralismo, Interculturalidade, Decolonialidade e as Transformações nos Estados Latino- } \\
\text { americanos }\end{array}$ & 2016 \\
\hline
\end{tabular}

